\title{
BMJ Open Design, implementation and reporting strategies to reduce the instance and impact of missing patient-reported outcome (PRO) data: a systematic review
}

\author{
Rebecca Mercieca-Bebber, ${ }^{1,2}$ Michael J Palmer, ${ }^{3}$ Michael Brundage, ${ }^{3}$ \\ Melanie Calvert, ${ }^{4}$ Martin R Stockler, ${ }^{1,5}$ Madeleine T King ${ }^{1,2}$
}

To cite: Mercieca-Bebber $\mathrm{R}$, Palmer MJ, Brundage M, et al. Design, implementation and reporting strategies to reduce the instance and impact of missing patientreported outcome (PRO) data: a systematic review. BMJ Open 2016;6:e010938. doi:10.1136/bmjopen-2015010938

- Prepublication history and additional material is available. To view please visit the journal (http://dx.doi.org/ 10.1136/bmjopen-2015010938).

Received 22 December 2015 Revised 4 May 2016 Accepted 18 May 2016

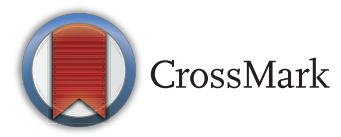

For numbered affiliations see end of article.

Correspondence to Rebecca Mercieca-Bebber; Rebecca.Mercieca@sydney. edu.au

\section{ABSTRACT}

Objectives: Patient-reported outcomes (PROs) provide important information about the impact of treatment from the patients' perspective. However, missing PRO data may compromise the interpretability and value of the findings. We aimed to report: (1) a non-technical summary of problems caused by missing PRO data; and (2) a systematic review by collating strategies to: $(A)$ minimise rates of missing PRO data, and (B) facilitate transparent interpretation and reporting of missing PRO data in clinical research. Our systematic review does not address statistical handling of missing PRO data.

Data sources: MEDLINE and Cumulative Index to Nursing and Allied Health Literature (CINAHL) databases (inception to 31 March 2015), and citing articles and reference lists from relevant sources.

Eligibility criteria: English articles providing recommendations for reducing missing PRO data rates, or strategies to facilitate transparent interpretation and reporting of missing PRO data were included.

Methods: 2 reviewers independently screened articles against eligibility criteria. Discrepancies were resolved with the research team. Recommendations were extracted and coded according to framework synthesis. Results: 117 sources (55\% discussion papers, $26 \%$ original research) met the eligibility criteria. Design and methodological strategies for reducing rates of missing PRO data included: incorporating PRO-specific information into the protocol; carefully designing PRO assessment schedules and defining termination rules; minimising patient burden; appointing a PRO coordinator; PRO-specific training for staff; ensuring PRO studies are adequately resourced; and continuous quality assurance. Strategies for transparent interpretation and reporting of missing PRO data include utilising auxiliary data to inform analysis; transparently reporting baseline PRO scores, rates and reasons for missing data; and methods for handling missing PRO data.

Conclusions: The instance of missing PRO data and its potential to bias clinical research can be minimised by implementing thoughtful design, rigorous methodology and transparent reporting strategies. All members of the research team have a responsibility in implementing such strategies.

\section{Strengths and limitations of this study}

- This systematic review collates practical strategies to minimise the problem of missing patientreported outcome (PRO) data. Recommendations were retrieved from 117 multidisciplinary sources and potential drawbacks of each recommendation are presented.

- Missing PRO data may be preventable in many cases by implementing rigorous study design and methodological strategies, as described in this review.

- In some clinical research settings, missing PRO data is not avoidable due to deteriorating health status of the participants. Strategies to minimise the potential for bias caused by missing PRO data are described.

- This paper discusses one aspect of PRO data quality: data completeness. Many other factors also contribute to high-quality PRO data, including but not limited to appropriateness of PRO measures, timing of PRO assessment, ensuring patients self-complete and clinical versus statistical significance of findings.

- This review excludes non-English sources. The non-English publications may have been relevant; however, given the repetition of themes found in our 117 included sources we do not believe that these would significantly affect our findings.

Patient-reported outcomes (PROs), including health-related quality of life (HRQOL) and specific symptoms, provide unique information about the effect of disease and treatment on the patient. PRO research evidence is crucial for informed clinical and policy decision-making, and is increasingly being used to inform labelling claims for medical products. ${ }^{1-3}$ The quality and value of PRO evidence is contingent on a number of factors, including: provision of a clear rationale for PRO assessment, the choice of PRO measure, the timing of PRO assessments, and ensuring the responses are the patient's 
own. One critical PRO quality assurance issue is missing data, defined as "...values that are not available and that would be meaningful for analysis if they were observed" (ref. 4, p. 1355). Conversely, researchers may measure 'PRO assessment compliance', which refers to the number of completed questionnaires received as a proportion of the number expected, given the study design, and the number of patients still alive and enrolled in the study. ${ }^{5}$ Both definitions acknowledge that questionnaires are not expected from patients who have died. ${ }^{4-6}$

The practical and methodological issues associated with missing PRO data received considerable attention in the literature in the 1990s. An expert workshop on the prevention and analysis of missing PRO data in trials led by international cancer trials groups was held in 1996, with findings published in a dedicated special issue of Statistics in Medicine. ${ }^{7}$ Yet problems with missing PRO data persist; high rates of missing PRO data continue to be reported in clinical trials, ${ }^{8-10}$ and PRO compliance rates are sometimes so poor that PRO data are not analysed. ${ }^{11}$

Persisting PRO compliance problems may reflect the sporadic attention the issue has received in the literature over the past 20 years, ${ }^{4}$ most of which is targeted to statisticians handling missing PRO data during analysis. This is problematic for four reasons: first, content targeted at statisticians may be conceptually and technically inaccessible to non-specialists; second, content addressing statistical handling of missing data does not acknowledge that some missing PRO data is preventable through study design and implementation; third, it promotes an attitude that the problem of missing data is the sole responsibility of the statistician; and fourth, appropriate statistical handling of missing PRO data is often contingent on other research data, and this will require consideration at the trial design stage. The broader research team should understand the issues associated with missing data, and their role in minimising related problems. This team includes individuals involved in study design and planning; recruitment; data collection; quality assurance; and analysing, interpreting or reporting of the results. To the best of our knowledge, there has not been a systematic review targeting the role of the broader research team in maximising PRO compliance rates, and minimising the problem of missing PRO data.

This paper has two aims, and is accordingly structured in two parts:

1. To summarise the problems created by missing PRO data in a format accessible to anyone involved in designing, conducting or analysing clinical research.

2. To systematically review the multidisciplinary literature to identify and collate strategies relevant to the entire research team to:

A. Maximise PRO compliance rates through study design and implementation;

B. Reduce the potential for biased interpretation caused by missing PRO data through PROspecific strategies for research design, implementation and reporting.
PART 1: THE PROBLEM OF MISSING PRO DATA-A SUMIMARY OF THE ISSUES

Missing PRO data create challenges for data analysis, and can compromise the interpretability and value of PRO findings for three major reasons: first, missed observations reduce study power. ${ }^{12}$ Studies with secondary PRO end points are usually sufficiently powered for PRO analyses when the sample size calculation is based on a survival primary end point (eg, progression-free survival) because these typically require larger sample sizes. However, a high proportion of missing PRO data will substantially reduce power and inflate standard error. ${ }^{13}$ This increases the risk of type 2 errors, that is, false-negative findings.

Second, and more problematically, missing data may be related to the measured outcome (ie, HRQOL, pain, etc) ${ }^{12}$ For example, non-completers who dropped out of Southwest Oncology Group trials due to death had worse HRQOL at baseline, and at time of drop out than other participants. ${ }^{5}$ In many cases, this type of missing PRO data is unavoidable, yet it cannot be ignored as doing so may lead to biased estimates-the extent of which is impossible to calculate. ${ }^{13}$

Third, the presence of missing data undermines randomisation, and makes intention-to-treat analyses (analysing according to randomised groups) less valid as missing data create a need to make assumptions about the data that are not always verifiable. ${ }^{14}$

\section{Difficulties in statistically handling missing PRO data}

There are many options for statistically handling missing PRO data. Each method makes assumptions about the missing data mechanism, ${ }^{15}$ which is a fairly technical system for classifying missing data according to their probable cause (see box 1). The challenge is to handle missing data in a way that closest resembles the true, albeit unverifiable, missing data mechanism, since the mechanism often has a greater impact on research results than does the proportion of missing data. ${ }^{16}$ To use a simple example-if PRO data are truly missing not at random (MNAR; eg, missing due to declining health), but the analysis method used assumes missing data are missing completely at random (eg, missing due to institution error) by excluding cases with missing data, then the analysed data represents only the betterperforming patients. Therefore, in addition to some loss of study power, the findings may falsely indicate that PROs are more favourable than is the true case, thus potentially leading to biased interpretation of change over time within groups, or of between-group differences. ${ }^{13}$ If the missing data appear MNAR, and are handled and interpreted sensibly (within the specific clinical and study context), the risk of introducing bias is reduced. Although statistical approaches are available, it is critical to prevent missing data, where possible, rather than to rely solely on statistical approaches. Prevention, statistical handling, interpretation and transparent reporting of missing PRO data are 


\section{Box 1 The missing data mechanism}

\section{Missing completely at random (MCAR)}

The probability of missing data is unrelated to past, current and future patient-reported outcome (PRO) scores/health status such as administrative errors. ${ }^{18}$ MCAR assumes the participants with missing data are a random sample of the whole sample. $^{18}$ Therefore, assuming the study is adequately powered, the results should not be altered too much if the MCAR are ignored in analysis; however, the standard error of the estimates will be inflated. ${ }^{19}$ Many examples of MCAR are caused by poor study design and implementation, and are hence 'preventable' sources of missing PRO data.

- Missing at random (MAR)

The probability of missing data depends on observed data or a fixed covariate, but not on the current (missing) or future PRO scores; for example, if a particular cultural group has a high proportion of missing data and patients from this group tend to have poorer PRO scores. ${ }^{13}$ Depending on whether the variable contributing to the likelihood of missing data is 'informative' (related to measured health outcome) or 'ignorable' (unrelated), using a statistical method that ignores MAR may distort the findings, potentially introducing bias. ${ }^{19}$ MAR is difficult to ascertain, but methods are available to test for (albeit with some uncertainty ${ }^{12} 20$ ) and analyse MAR PRO data. ${ }^{1221}$

- Missing not at random (MNAR)

The probability of missing data depends on current and future unobserved scores. PRO scores previously observed are constant but would decline at (or after) drop out, and the process of decline is not observed. ${ }^{18}$ Data that meet the MNAR assumption are always 'informative', that is, missing due to the patient's declining health status, but the extent of decline is not known because it is not observed. Few methods are available for unbiased analysis of MNAR. ${ }^{21}$

complementary strategies. It is recommended that statistical handling of missing PRO data be undertaken by a statistician as the methods used are technical. Therefore, statistical handling of missing PRO data is not addressed in our systematic review below. Interested readers are referred to Bell and Fairclough ${ }^{17}$ for detailed discussion.

\section{PART 2: A SYSTEMATIC REVIEW OF STRATEGIES TO MAXIMISE PRO COMPLIANCE RATES AND REDUCE THE POTENTIAL FOR BIAS}

Part 1 of this paper summarised the problem of missing PRO data for the analysis and interpretation of study results. This motivates part 2 of our paper: a systematic review of strategies for all research team members to assist in minimising the problem of missing PRO data.

\section{Systematic review methods}

\section{Search strategy}

MEDLINE and Cumulative Index to Nursing and Allied Health Literature (CINAHL) databases were systematically searched using a search strategy (see online supplementary appendix A) which combined PRO terms with missing data and compliance terms. These databases were chosen as they canvassed the disciplines of interest to our review, and because they indexed key papers already known to the authors. The search strategy was developed by first reviewing literature to identify key search terms. We sought advice from three librarians with expertise in systematic reviews to ensure all relevant Medical Subject Headings (MeSH) were addressed, and conducted several pilot searches to capture targeted papers. The MEDLINE search was restricted to English language articles. Reference lists and citations of included papers retrieved in the database search were screened (by title) for additional relevant sources, using the same eligibility criteria.

\section{Eligibility criteria}

Papers were included if they provided guidance or recommendations for minimising/preventing missing PRO data in prospective research designs, or for transparent interpretation and reporting of missing PRO data to minimise risk of potential interpretation bias. We excluded non-English articles; conference presentations; research protocols; papers discussing statistical handling of missing PRO data, instrument development, proxyreporting, patient-reported behaviours (smoking, drug use, etc), non-patient samples and papers reporting general study/trial drop-out rates.

\section{Study selection}

Two reviewers (RM-B and MJP) independently screened article titles and abstracts using the eligibility criteria. Screening discrepancies were discussed and settled with two senior authors (MB and MTK). Abstracts that appeared to meet the criteria were obtained in full text and assessed against the same criteria. Our search and study selection process complied with Preferred Reported Items for Systematic Reviews and Meta-Analyses (PRISMA) guidelines ${ }^{22}$ (see online supplementary appendix B).

\section{Extraction and coding of recommendations}

Recommendations were extracted, coded and analysed using framework synthesis methodology (RM-B).$^{23}{ }^{24} \mathrm{An}$ a priori framework was used to organise recommendations into three categories (study design and planning, during active study, reporting), then coded according to the specific recommendation (eg, minimise patient burden). These codes were refined and developed during the process, and organised into three code levels on completion. For example, the major category of 'minimise patient burden' was subcategorised into 'assistance to patients', 'questionnaire content', 'length of assessments' and 'validated questionnaires'. Each subcategory was further categorised for specificity; for example, the third-level categories for 'length of assessments' includes 'fewer assessments', 'shorter questionnaire', 'use screening questions', etc. Three reviewers (MTK, MJP, MB) each checked $10 \%$ of extractions. Frequencies of each unique recommendation were calculated, and potential 
drawbacks of each recommendation were described. Two reviewers (MJP, MTK) checked $100 \%$ of the final results tables. Disagreements were discussed as a team to achieve consensus.

\section{RESULTS}

One hundred and seventeen articles (listed in online supplementary appendix C) met the inclusion criteria (figure 1). These arose from oncology, palliative care and other disease-specific and non-disease-specific PRO literature (table 1).

\section{Design strategies to minimise the problem of missing PRO data}

Recommendations for reducing the problem of missing PRO data through study design are summarised in 12 categories in table 2: PRO assessment schedule: a clinically informative and feasible assessment schedule should be defined, with acceptable assessment time windows and stopping rules; collection of auxiliary or supporting data: collect information to facilitate unbiased interpretation of PRO data in the presence of missing data, such as clinician-rated health status, observational or proxyreported data; eligibility criteria: include literacy and language requirements, and the need for a valid baseline PRO assessment; feasibility issues: considerations for determining required resources and ensuring the PRO study is feasible; guidance: for trial team members to standardise administration and maximise PRO completion rates; mode of questionnaire administration (MOA): MOA should be feasible and acceptable, and impact on PRO completion rates should be considered; minimise participant burden: employ strategies to ensure PRO assessment is easy and acceptable to participants; PRO measure. PRO measures should be clinically relevant, validated, and acceptable to patients; PROs part of the trial: incorporate PROs into all relevant study documents and ensure the team is committed to the PRO study; quality assurance: prepare databases, study guidance and procedures with ongoing quality assurance in mind; sample: ensure the PRO sample size is representative and sufficient for planned analyses; team involved in design/protocol development: involve a multidisciplinary team, including PRO experts, clinicians, nurses, site coordinators, patients and others.
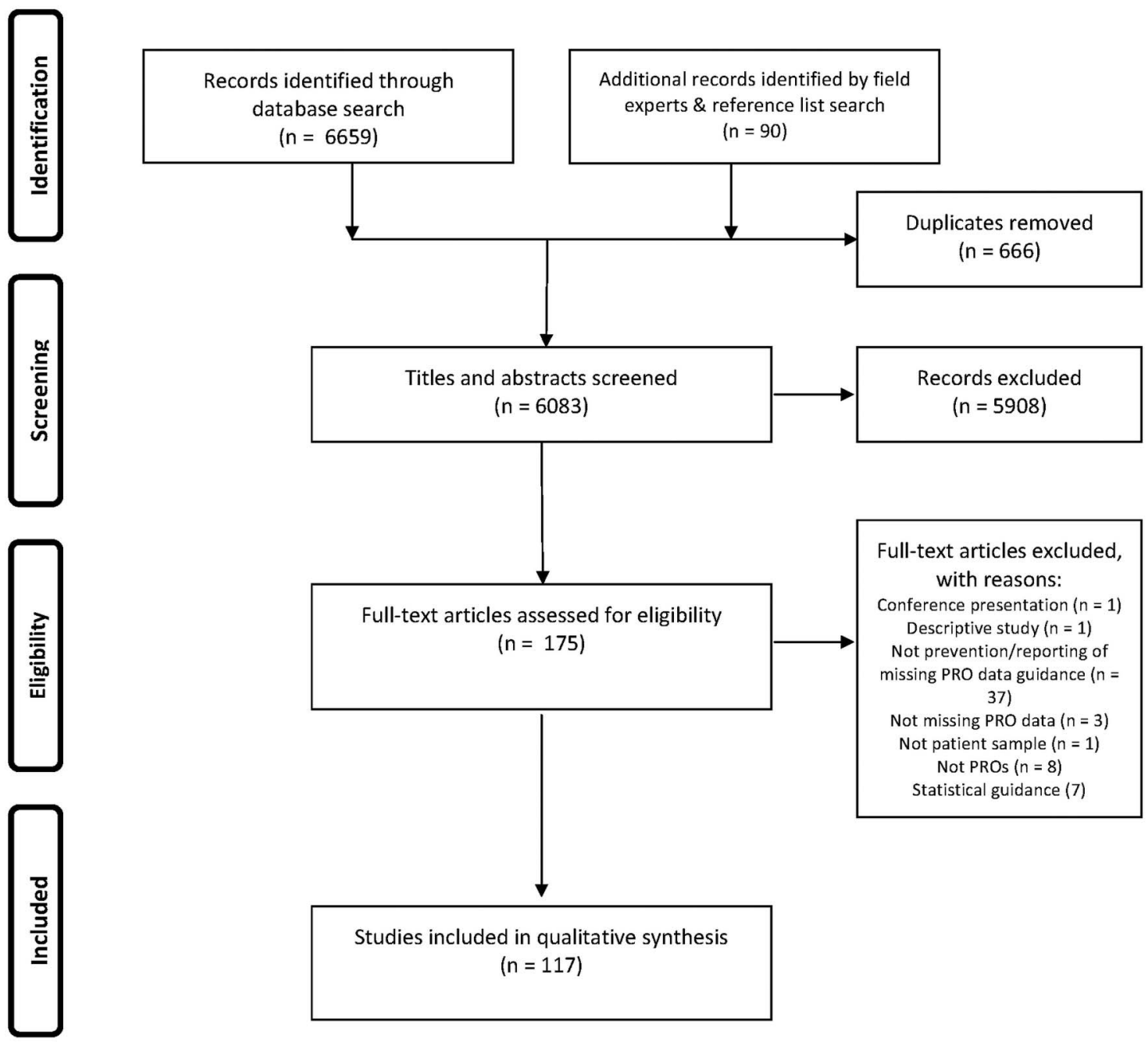

Studies included in qualitative synthesis $(n=117)$

Figure 1 PRISMA flow diagram. PRO, patient-reported outcome. 
Table 1 Characteristics of included sources

\begin{tabular}{lrr}
\hline & N & Per cent \\
\hline Total & 117 & 100.0 \\
Disease & & \\
$\quad$ Cardiovascular disease & 3 & 2.6 \\
Non-specific & 22 & 18.8 \\
Oncology & 65 & 55.6 \\
Orthopaedics & 3 & 2.6 \\
Pain & 2 & 1.7 \\
Palliative care & 6 & 5.1 \\
Women's health & 3 & 2.6 \\
Other & 13 & 11.1 \\
Publication type & & \\
Discussion/review & 64 & 54.7 \\
Guideline & 3 & 2.6 \\
Meta-analysis & 2 & 1.7 \\
Original research & 30 & 25.6 \\
Systematic review & 9 & 7.7 \\
Text book & 6 & 5.1 \\
Other & 3 & 2.6 \\
Year of publication (range) & & \\
1988-1989 & 3 & 2.6 \\
1990-1999 & 40 & 34.2 \\
2000-2009 & 47 & 40.2 \\
2010-2015 & 27 & 23.1 \\
\hline
\end{tabular}

The five most frequently recommended design strategies were: baseline PRO completion as an eligibility criterion $(n=28)$, develop guidance for site staff to standardise the administration of PRO questionnaires $(n=27)$, minimise the length of questionnaires to reduce patient burden $(\mathrm{n}=18)$, align PRO assessment time points to clinic visits $(n=16)$ and ensure recruiting sites have sufficient resources to run the PRO study $(n=15)$.

\section{Implementation strategies to minimise the problem of missing PRO data}

Recommendations for minimising the problem of missing PRO data while the PRO study is active were coded into seven categories in table 3: administration procedures: standardised procedures, particularly for site staff, to maximise PRO compliance; patient education and engagement: education about the value of PROs in the study, and engagement through study updates or incentives; maintaining patient records: contact details and health status should be kept updated; quality assurance. procedures and active communication to monitor compliance and intervene if issues are apparent; site coordinator: appoint an individual responsible for PRO assessment at recruiting sites with appropriate organisational and communication skills; team involved in study implementation: broader trial team must stay engaged and committed to the PRO study, and work together towards its successful completion; and staff training. provide initial and ongoing training about PROs, communication skills, methodology; and formats of such training. The most frequently recommended implementation strategies were: use a PRO completion cover sheet for standardised recording of reasons for missing PRO data $(\mathrm{n}=39)$, appoint a site coordinator responsible for PRO assessments $(\mathrm{n}=33)$, send reminders about upcoming PRO assessments to site staff $(n=30)$, ensure site staff check completed PRO questionnaires for missed items while the patient is still in the clinic $(n=29)$ and centrally monitor PRO compliance in real-time $(\mathrm{n}=27)$.

\section{Strategies for reporting studies with missing PRO data}

Strategies for reporting studies with missing PRO data are presented in table 4 . These addressed a need for clearly reported methodology, including analysis methods; describing the sample, including baseline scores; defining and providing compliance rates; comparing participants with and without missing PRO data; providing reasons for missing data and discussing the impact of missing data on generalisability of findings. The most frequently recommended details to report were: rates of missing PRO data $(n=26)$, reasons/types of missing PRO data $(n=15)$, how missing data were handled for the analysis $(n=9)$, discussion of the potential for bias caused by missing PRO data $(n=6)$, and clinical and demographic characteristics of the sample, including baseline PRO scores $(n=5)$.

\section{DISCUSSION}

This paper summarises the problems created by missing PRO data, and highlights the need for all members of the research team to assist in minimising the problem of missing data. Our systematic review identified and synthesised a range of practical strategies for all research team members to maximise PRO compliance and reduce the problem of missing PRO data through design, implementation and reporting. These strategies highlight the need for thoughtful planning and incorporation of PROs into all research documents. ${ }^{25-30}$ PRO study design should balance the need for sufficient PRO data with the capacity of patients to self-report, and the feasibility and practicality of site staff to collect it at informative time points. ${ }^{31-33}$ Previous research has demonstrated that involving experienced data collection personnel in PRO study development is crucial to achieving high compliance rates. ${ }^{25}{ }^{34}$ Strategies for minimising bias caused by missing PRO data involve utilising auxiliary data to inform valid analysis according to the likely missing data mechanism; this must be planned for during study design.

While the PRO study is active, high-level support of the sponsor and advocacy by the PRO expert on the research steering committee (or similar) is essential to emphasise the importance of PRO data. Given the timesensitive nature of PRO data, quality assurance strategies are crucial to maintaining high standards, particularly real-time monitoring of $\mathrm{PRO}$ completion rates to enable timely intervention if compliance falls below prespecified thresholds. ${ }^{35}$ Land $e t$ a ${ }^{25}$ found that targeted 


\section{Category}

Design

Topic

Assessment

schedule points
Specify PRO assessment time

Time point selection

(guidance on how to select

PRO assessment time points)

\section{Specific recommendation}

Specify the required PRO assessment time points Specify the minimum PRO data requirements (eg, 'baseline, on and off treatment, and and/or end of study' (ref. 5, p. 524) PRO assessment schedule if treatment schedule is disrupted (ie, will the PRO assessment schedule be altered if the treatment schedule is altered?) Align PRO assessments to clinic visits so that data may be captured while the patient visits the clinic

Align assessment schedule to a fixed reference point (for ease of calculating when PRO assessments are due) Allow sufficient breaks between PRO assessments

Assess PROs of palliative care patients weekly

Balance the number of required $\mathrm{PRO}$ assessments (not too few, not too many) Consider patient treatment and expected survival when
N recommendations* Potential drawbacks

None

May create impression that additional PRO

assessments are not important

None

Fairclough (2010) Beitz (1996)

Bernhard, Cella (1998)

Source/s: first author (year). Full citations are provided as Online

Supplementary Appendix C

Bernhard, Gusset (1998),

gh (2010)

Clinic visits may not be most informative to capture particular treatment effects (eg, chemotherapy toxicity) May be burdensome to participants to attend clinic for regular assessments

May be burdensome to participants to attend regular assessments

May not be feasible if investigators wish to capture acute disease/ treatment effects or their frequency via PROs

Does not consider when PRO assessment would be most meaningful

None

None
Bernhard, Cella (1998) Moinpour (1998), Movsas (2003), Aaronson (1990), Land (2007), Walker (2003), Calvert (2004), Sprague (2003), Revicki (2005), Fairclough (2010), Kyte (2013), Blazeby (2003) Simes (1998)

Bernhard, Cella (1998)

Sherman (2005)

Tang (2002)

Revicki (2005), Fairclough (2010)

Kaasa (2002), Hahn (1998), Atherton (2006) 


Design $\quad$ Topic

Specific recommendation

N recommendations
Source/s: first author (year). Full citations are

provided as Online

planning assessment

schedule (added note: avoid

PRO assessments beyond the

point of expected median

survival)

Select clinically meaningful

time points (ie, ensure that

PRO assessments will be

taken at clinically informative

times, ie, to capture the

trajectory of treatment and

recovery)

Event-driven PRO

assessment for a subsample

(ie, rather than subjecting

entire sample to detailed PRO

assessments if they

experience certain clinical

events, it may minimise staff

effort and resources to restrict

these additional assessments

to a subsample only)

Focus on short-term outcomes

in patients with advanced

disease (focusing on

long-term outcomes in such

samples will lead to high rates

of missing PRO data, and

uninformative data)

Justify chosen PRO

assessment time points

Minimise PRO assessment

time points (select fewer time

points to minimise burden and

resource usage)

Shorter follow-up duration

(avoid following up patients for
May not be clinically meaningful to assess

short-term outcomes in al studies

None

May sacrifice important information by omitting

time points, for example,

differences between

treatment arms

May sacrifice important information by ceasing
Ganz (2007), Jordhoy (1999) Tang (2002)

Bernhard, Cella (1998),

Simes (1998)

Ganz (2007)

Ganz (2007)

Bernhard, Cella (1998), Macefield (2013), Cella

(1995)

Little, Cohen (2012) 


\begin{tabular}{|c|c|c|c|c|c|}
\hline \multicolumn{6}{|l|}{ Category } \\
\hline \multirow[t]{7}{*}{ Design } & Topic & Specific recommendation & N recommendations ${ }^{*}$ & Potential drawbacks & $\begin{array}{l}\text { Source/s: first author } \\
\text { (year). Full citations are } \\
\text { provided as Online } \\
\text { Supplementary Appendix C }\end{array}$ \\
\hline & & $\begin{array}{l}\text { a longer period of time as } \\
\text { participants are more likely to } \\
\text { drop out over time) }\end{array}$ & & $\begin{array}{l}\text { PRO assessment too early } \\
\text { in some studies. Some } \\
\text { studies may be interested } \\
\text { in long-term follow-up/ } \\
\text { survival outcomes. }\end{array}$ & \\
\hline & Treatment failure/cessation & $\begin{array}{l}\text { Continue PRO assessments } \\
\text { after treatment failure }\end{array}$ & 6 & $\begin{array}{l}\text { May be difficult to engage } \\
\text { or contact participants } \\
\text { beyond point of treatment } \\
\text { failure }\end{array}$ & $\begin{array}{l}\text { Hao (2010), Little, } \\
\text { D’Agnostino (2012), } \\
\text { Sprangers (2002), Chassany } \\
\text { (2002), Cella (1995), Cella } \\
\text { (1994) }\end{array}$ \\
\hline & & $\begin{array}{l}\text { Specify procedures for } \\
\text { contacting participants after } \\
\text { treatment cessation }\end{array}$ & 3 & None & $\begin{array}{l}\text { Cella (1994), Revicki, Hao } \\
\text { (2010) }\end{array}$ \\
\hline & & $\begin{array}{l}\text { Specify the PRO assessment } \\
\text { stopping rule (ie, under what } \\
\text { circumstances should PRO } \\
\text { assessments discontinue) }\end{array}$ & 3 & None & $\begin{array}{l}\text { Bell (2014), Kaasa (1992), } \\
\text { Young, de Haes (1999) }\end{array}$ \\
\hline & Time windows & $\begin{array}{l}\text { Define PRO assessment time } \\
\text { windows (ie, baseline } \\
\text { assessment time window } \\
\text { should always end before the } \\
\text { intervention/treatment } \\
\text { commences. Follow-up } \\
\text { assessment time windows } \\
\text { should border the period in } \\
\text { which treatment effects of } \\
\text { interest are anticipated, for } \\
\text { example, if the time point is } \\
1 \text { week postsurgery, a valid } \\
\text { assessment may occur } \\
\text { anytime between } 4 \text { and } \\
12 \text { days postsurgery). }\end{array}$ & 12 & None & $\begin{array}{l}\text { Bernhard, Cella (1998), Cella } \\
\text { (1994), Wisniewski (2006), } \\
\text { Blazeby (2003), Hopwood } \\
\text { (1996), Bernhard, Peterson } \\
\text { (1998), Fayers (1997), } \\
\text { Hopwood (1998), Revicki } \\
\text { (2005), Fairclough (2010), } \\
\text { Cella (1995) }\end{array}$ \\
\hline & & $\begin{array}{l}\text { Flexible/large time windows } \\
\text { (very narrow time windows } \\
\text { may be logistically infeasible } \\
\text { to implement and so risk of } \\
\text { missing PRO data may be } \\
\text { reduced by setting larger time } \\
\text { windows) }\end{array}$ & 3 & $\begin{array}{l}\text { Not all time windows can } \\
\text { be flexible, particularly } \\
\text { when assessing acute } \\
\text { effects of treatment }\end{array}$ & $\begin{array}{l}\text { Bernhard, Cella (1998), Little, } \\
\text { Cohen (2012), McMillan } \\
\text { (2003) }\end{array}$ \\
\hline
\end{tabular}




\section{Design}

Collect additional/ supporting data

(which can be

used during PRO

data analysis and

interpretation)

\section{Topic}

Auxiliary data (to assist interpretation if there are some missing PRO data). Suggestions of types of auxiliary data in the next column

\section{Specific recommendation}

Additional information about non-responders (type of

additional information

unspecified)

\section{Clinical data}

Health status (clinician-rated quality of life index, Karnofsky or ECOG performance status)

Comorbidity data

Concomitant medications

Observation data

Participant clinical data

Participant demographics

Proxyt reports when participant is no longer able to self-complete

Toxicity data recommendations*

Potential drawbacks

Requires prespecification, and additional time and resources to collect

Requires additional time and resources to collect Requires additional clinician time

Requires additional time and resources to collect Requires additional time and resources to collect Requires additional time and resources to collect

None

None

Proxy reports are not always concordant with participant self-reports.

Care must be taken when interpreting proxy data. This is a specialist subject and additional reading is recommended for investigators considering

to use proxy

assessment. $^{64}$

Requires additional time and resources to collect, if

not already being collected as part of the study
Source/s: first author (year). Full citations are

provided as Online Supplementary Appendix C

Kim (2004)
Newgard (2010)

Coates (1998), Bell (2014), Bernhard, Cella (1998), Simes (1998), Revicki (2005), Fairclough (2010) Bernhard, Cella (1998)

Beitz (1996)

Kaasa (2002)

Newgard (2010)

Altman (2007), Newgard (2010)

Bernhard, Cella (1998),

Chassany (2002), Fayers

(1997), Jordhoy (2010),

Kleinpell-Nowell (2000), Kyte (2013), Machin (1998), Moynihan (1998), Peruselli (1997), Revicki (2005), Rock (2007), Simes (1998),

Sprangers (2002), Stewart

(1992), Taphoorn (2010),

Walker (2003)

Fairclough (2010), Revicki (2005) 
Design Topic

Eligibility criteria for PRO study (suggestions of specific eligibility

or inclusion

criteria)

Baseline PRO completion

Consider the participants ability to complete PROs

include baseline PRO

completion as an eligibility criterion)
Include patients with minimal level of impairment (as per

baseline PRO) to ensure inclusion of patients with severe disease Specific recommendation Unspecified (use an alternative to PRO in final weeks of life)

Collect reasons for missing PRO data

Source/s: first author (year). Full citations are provided as Online Supplementary Appendix C Jordhoy (2010) Requires additional time and resources to collect. Additional drawbacks may be apparent depending on specific alternative measure/s used.

See 'cover sheet' section in administration procedures in table 3

Include-'participant must be able to complete PROs' as an

Ability to complete PRO assessments may change over the course of treatment. Results may not be generalisable to all patients.

Exclude patients with

May reduce the sample size/power of PRO study. Results may not be generalisable to all from the PRO study only (ie, these participants are able to take part in other aspects of the trial, but will not be included in the PRO study) patients.

None

May lead to selection bias May impact generalisability of results 
Category

Design

Topic

Surviving long enough to complete PROs (palliative

care)

Participants' willingness to complete PROs

Feasibility issues of PRO studies

Pilot study

\section{Specific recommendation}

N

(1)

Determine feasibility of PRO study (potential issues,

resources required and/or sample size), and acceptability by conducting a pilot study

Determine compliance targets by conducting a pilot study

Conduct a pilot study to determine average time to complete PRO measures Use the PRO pilot study as a training opportunity for less experienced staff

Ensure there is sufficient funding for the PRO study and that the PRO study is included in study budget

Resource allocation-ensure recruiting sites are sufficiently resourced for the PRO study
Source/s: first author (year). Full citations are

provided as Online Supplementary Appendix C

Bakitas (2009), Jordhoy Difficult to estimate in some cases, so prognostic cues predictive of death may be more practical; may introduce selection bias.

May result in selection bias; patients more willing to take part in PRO study may differ systematically from non-participants.

Requires time and resources

(1999), Chassany (2002)

Fayers (1997), Sprague (2003)

Cella (1994), Cella (1995), Groenvold (1999), Hurny (1992), Moinpour (1989), Kleinpell-Nowell (2000),

Young, de Haes (1999),

Sherman (2005), Wisniewski (2006)

Requires a long pilot study to determine; significant time and resources

Requires time and resources

Requires time and resources

Funding can be difficult to obtain; however, it is possible to minimise costs of PRO studies at no cost to high-quality PRO research

Funding can be difficult to obtain across all sites especially if recruiting internationally or trans-nationally.
Kleinpell-Nowell (2000)

Cella (1995)

Bernhard, Cella (1998), Cella (1995), Coates (1998), Gotay (2005), Moynihan (1998)

Bernhard, Cella (1998), Bernhard, Peterson (1998), Hayden (1993), Hopwood (1998), Hopwood (1996), Kaasa (1992), Moinpour 
Source/s: first author (year). Full citations are provided as Online Supplementary Appendix C

(1998), Moynihan (1998), Revicki (2005), Scott (2004), Sprague (2003), Walker (2003), Wisniewski (2006), Young, de Haes (1999)

Ensure adequate staff at potential sites

Funding to employ new staff can be difficult to obtain

Minimise resources required 4 for the PRO study

Selection of recruiting sites

Select sites with good compliance record

Select sites with adequate resources performance

May limit the number of overly burden particular sites; potential for selection bias ${ }^{65}$ participants recruited Sites with adequate resources may not best compliance record. None
PRO administration guidance (for site staff)

General administration guidance aiming to standardise administration of PROs

RO-specific guidance for the research team
Care must be taken not to sacrifice quality of data or participants recruited; may

May limit the number of necessarily be sites with

May introduce bias if

Flexible processes across sites (There may be local variations in who is procedures differ too much between recruiting sites
Bernhard, Cella (1998), McMillan (2003)

Bernhard, Cella (1998)

Hurny (1992)

Bernhard, Peterson (1998), Calvert (2004), Cella (1994), Cella (1995), Fayers (1997), Friedman (1998), Ganz (1988), Hahn (1998), Hayden (1993), Hopwood (1998), Kaasa (1998), Kaasa (1992), Land (2007), Newgard

(2010), Osoba (1996), Osoba (1992), Sprangers (2002) Taphoorn (2010)

Vantongelen (1989), Walker (2003), Wisniewski (2006) Bernhard, Peterson (1998) 
therefore, procedures should

be flexible to accommodate such differences.)

Importance of complete data

must be stressed in PRO

None

administration guidance

Instructions to give to

participants must be specified

in PRO administration

guidance

Procedures for missed

assessments must be

specified in PRO

administration guidance

Staff roles must be specified

in PRO administration

guidance

Procedures for handling

special situations must be

specified in PRO

administration guidance

Protocol guidance 606163

Follow PRO protocol guidance

(investigators)

Develop protocol guidance for

investigators (trials groups)
MOA (ie, is the questionnaire administered in

hardcopy (pen

and paper)

electronically, over

the phone, etc)
Consider costs involved with each MOA

Choice of MOA

Consider impact of MOA on participants' willingness to disclose information
None

Not all difficult situations can be predicted in advance

None

None

None
Fayers (1997)

Wisniewski (2006)

Calvert (2004)

Poy (1993), Young de Haes (1999)

Hahn (1998), Hopwood (1998), Hopwood (1996), Revicki (2005)

Bernhard, Cella (1998),

Osoba (2007)

Osoba (1996)

Macefield (2013) 


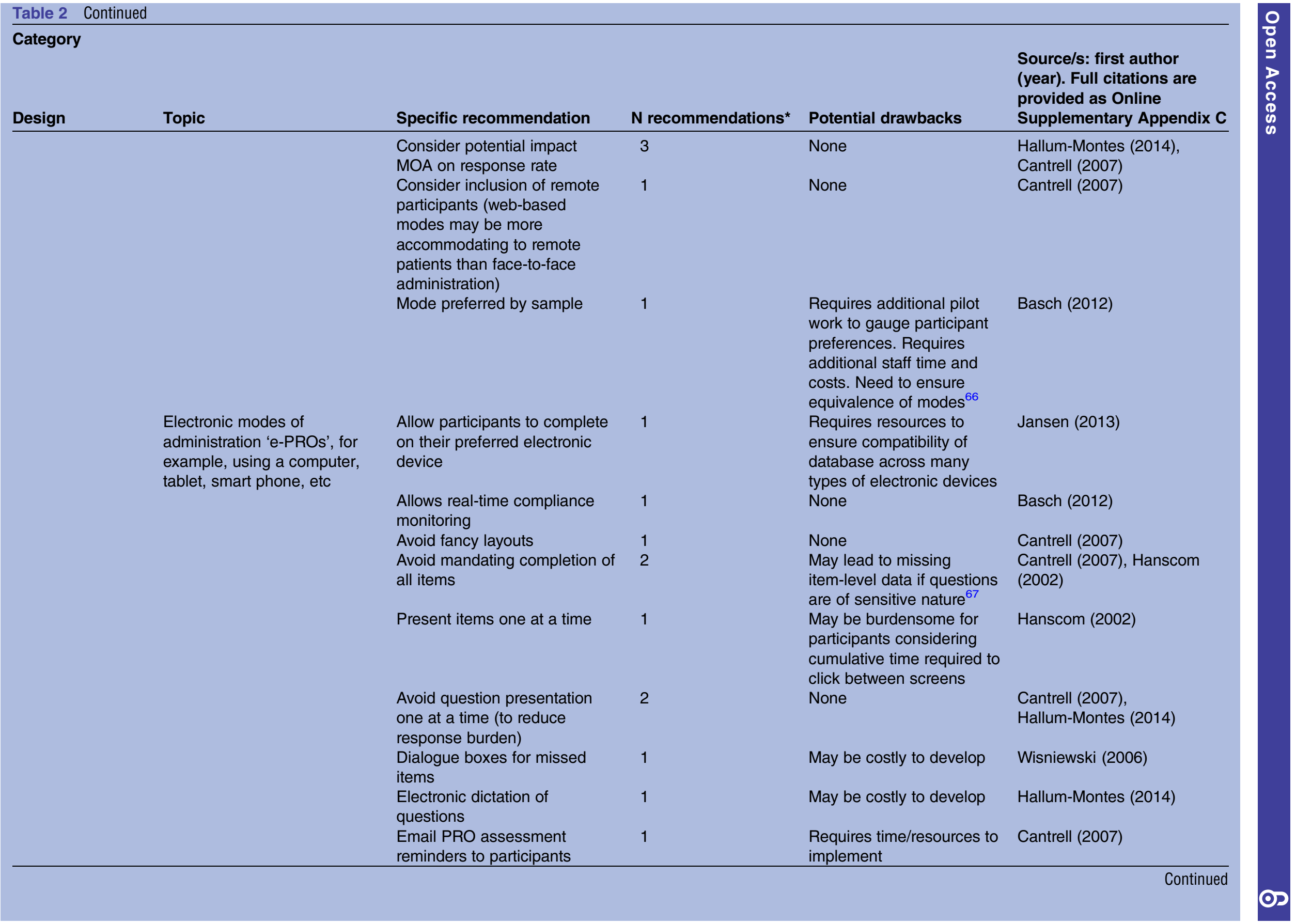




\begin{tabular}{|c|c|c|c|c|c|}
\hline Design & Topic & Specific recommendation & N recommendations ${ }^{*}$ & Potential drawbacks & $\begin{array}{l}\text { provided as Online } \\
\text { Supplementary Appendix C }\end{array}$ \\
\hline & \multirow{7}{*}{ Flexible MOA } & e-PROs encouraged & 1 & $\begin{array}{l}\text { e-PRO assessment may } \\
\text { not be acceptable to some } \\
\text { patient populations. } \\
\text { May be subject to } \\
\text { technical fault/data } \\
\text { protection/connectivity } \\
\text { issues }\end{array}$ & Basch (2012) \\
\hline & & $\begin{array}{l}\text { Keep assessment simple to } \\
\text { reduce risk of technical fault }\end{array}$ & 1 & None & Hjermstad (2012) \\
\hline & & Make all items mandatory & 1 & $\begin{array}{l}\text { May lead to incomplete } \\
\text { questionnaires if questions } \\
\text { are of a sensitive nature }\end{array}$ & Cantrell (2007) \\
\hline & & $\begin{array}{l}\text { Follow-up missed } \\
\text { assessments with alternate } \\
\text { mode (eg, if participant misses } \\
\text { a face-to-face visit in which } \\
\text { hardcopy PRO assessment } \\
\text { was scheduled, consider } \\
\text { calling the participant to } \\
\text { complete PRO over the } \\
\text { phone, or posting the } \\
\text { questionnaire to their home } \\
\text { address with reply-paid } \\
\text { envelope to return completed } \\
\text { questionnaire) }\end{array}$ & 4 & $\begin{array}{l}\text { Requires additional staff } \\
\text { time and resources }\end{array}$ & $\begin{array}{l}\text { Bernhard, Cella (1998), } \\
\text { Blazeby (2003) }\end{array}$ \\
\hline & & $\begin{array}{l}\text { Interview-administered } \\
\text { questionnaires for very sick } \\
\text { participants }\end{array}$ & 4 & $\begin{array}{l}\text { Requires additional staff } \\
\text { time }\end{array}$ & $\begin{array}{l}\text { Kaasa (1998), Stewart } \\
\text { (1992), Moynihan (1998), } \\
\text { Chassany (2002) }\end{array}$ \\
\hline & & Offer more than one MOA & 2 & $\begin{array}{l}\text { May complicate data entry } \\
\text { procedures or procedures } \\
\text { for returning PRO data }\end{array}$ & $\begin{array}{l}\text { Bernhard, Cella (1998), } \\
\text { Gotay (2005) }\end{array}$ \\
\hline & & $\begin{array}{l}\text { Negotiate with the site as to } \\
\text { their preferred MOA }\end{array}$ & 1 & $\begin{array}{l}\text { May be infeasible to } \\
\text { implement different modes } \\
\text { between sites-some sites } \\
\text { may have to compromise }\end{array}$ & Simes (1998) \\
\hline & Interview-administered MOA & $\begin{array}{l}\text { Interview-administered MOA } \\
\text { may improve response rates. }\end{array}$ & 1 & $\begin{array}{l}\text { Requires additional staff } \\
\text { time and resources }\end{array}$ & Fowler (1996) \\
\hline
\end{tabular}


Design Topic Postal MOA

Patient burdenminimise

Minimise patient burden (general statement)

Offer assistance to participants to complete PROs (to reduce burden PRO completion)

\section{Content}

(c)

Clearlsimnaire if needed

instructions of questionnaires

Reduce overlap in

questionnaire items

Collect relevant PRO data only

assessment in clinic and

subsequent assessments by

self-addressed envelope for easy return of completed questionnaires (when using postal MOA)

Additional assistance-

ildcare (offer to provide child

in

clinic visits in which PRO

ents are scheduled)

Additional assistance-travel

offer to arrange or fund travel

participants to the clinic for

PRO assessments)

Avoid the need for a clinic visit

where possible

Source/s: first author (year). Full citations are

provided as Online Supplementary Appendix C Kaasa (1998)

\section{None}

1

Requires additional

resources

Requires additional resources

May be difficult to engage participants away from the

clinic

Requires additional staff

time and resources

None

None

None
Kleinpell-Nowell (2000), Poulter (1997)

Aaronson (1990), Hahn (1998), Little, D’Agostino (2012), Macefield (2013) McMillan (2003), Revicki (2005), Walker (2003) Bell (2014)

Bell (2014)

Little, Cohen (2012)

Sprague (2003)

Young, de Haes (1999)

Fallowfield (1998), Walker

(2003), Young, de Haes

(1999)

Bernhard, Cella (1998), Little, Cohen (2012) 


\begin{tabular}{|c|c|c|c|c|}
\hline Design & Topic & Specific recommendation & N recommendations* & Potential drawbacks \\
\hline & \multirow[t]{5}{*}{ Format } & $\begin{array}{l}\text { Avoid using multiple } \\
\text { questionnaires }\end{array}$ & 1 & None \\
\hline & & $\begin{array}{l}\text { Avoid written (free text) } \\
\text { answers }\end{array}$ & 1 & None \\
\hline & & Clear/simple format & 6 & None \\
\hline & & Large/clear font & 1 & $\begin{array}{l}\text { May increase printing } \\
\text { costs if larger font adds } \\
\text { pages to the questionnaire } \\
\text { booklet }\end{array}$ \\
\hline & & Professional format (eg, use & 3 & None \\
\hline
\end{tabular}

Source/s: first author (year). Full citations are

provided as Online Supplementary Appendix C

Chassany (2002)

Friedman (1998)

Conroy (2003), Little Cohen

(2012), Kleinpell-Nowell

(2000), Bernhard, Cella

1998), Revicki (2005), Sloan

(2007)

study letterhead on printed

None

questionnaires, use consistent

formatting, etc)

Single-sided printing (some

Environmental burden

reports suggest that

May increase printing

costs due to additional

pages in the questionnaire

overlook the underside of

questionnaires printed

double-sided)

Uniform presentation format

booklet

(a consistent formatting

approach appears more

professional and may be

easier for participants to

follow, potentially reducing risk

of participants skipping items

inadvertently or due to lack of

understanding)

Length of assessments Consider participant health-

sicker participants will not be

May not be possible if

using more than one

questionnaire

able to complete long PRO

assessments

Fewer assessment time points

(ie, PRO assessments that

occur regularly may be overly burdensome)

None

May sacrifice important information by assessing PRO less often
Kleinpell-Nowell (2000), Hurny (1992)

Fairclough (2010), Revicki

(2005)

Revicki (2005), Sloan (2007)

Bernhard, Peterson (1998)

Moinpour (1989), Stewart (1992), Young, de Haes (1999)

Bernhard, Cella (1998), Little, Cohen (2012), Chassany (2002), Ganz (1988), Jansen (2013), Revicki (2005), 
Source/s: first author (year). Full citations are provided as Online Supplementary Appendix C

Fallowfield (1998), Hurny (1992), Hao (2010)

Use validated questionnaires formatting that participants find

Continued participant engagement-use strategies engagement (also see table 3 ) to keep participants engaged throughout the life of the study/trial

Participant incentives for participating/completing PRO questionnaires
Fewer pages in e-PROs (eg, minimising the number of clicks between pages may reduce burden)

Shorter questionnaire

Limits the amount of information that can be assessed using PROs

Use CAT/screening questions allows for targeted question content and fewer items, to minimise burden)

Questionnaire items or burdensome may be addressed in response to feedback obtained during questionnaire validation

process

Adapt procedures to participant cultural group-

None

Steinhauser (2006)

Cantrell (2007)

Basch (2012), Basch (2014), Bell (2014), Bernhard, Cella (1998), Bernhard, Peterson (1998), Chassany (2002), Fairclough (2010), Hjermstad (2012), Hurny (1992),

Moinpour (1989), Revicki (2005), Rock (2007), Sadura (1992), Siddiqui (2014),

Young, de Haes (1999)

Requires additional set-up Hjermstad (2012) costs. Can be difficult to introduce a second non-electronic MOA if using CAT as questions administered will differ between participants

None

Kaasa (1992)

Requires time and resources

Wilcox (2001)

conduct background research

about the cultural groups

involved

Offer participants access to

care via/after trial/study
Requires time and resources
Blazeby (2003), Little, Cohen (2012), Little D'Agnostino (2012) 
Selecting a PRO Acceptable measures for measure

participants

Clinically relevant measures (select PRO measures that are clinically appropriate, that is, include questions about relevant issues to specific

disease/treatment)

Features to avoid in prospective PRO measures

Translated (validated) questionnaires
Specific recommendation

N

Offer participants financial

13

incentives

Offer participants non-financial incentives

Reimburse participants for their time/costs involved in participating (factor into study budget)

13

3

(1)

ran

tations

Avoid overlapping content/

highly correlated items

Avoid sensitive item content

(ie, participants are more likely

to skip items addressing

sensitive issues such as

sexuality or finances; so by

avoiding such items you may

minimise risk of missing PRO data)

\section{Potential drawbacks}

Requires time and

resources. Conflicting evidence about the effectiveness (in general population samples) ${ }^{68}$ and ethical issues in patient

populations

Requires time and resources. Conflicting evidence about the effectiveness (in general population samples) ${ }^{68}$ and ethical issues in patient populations

Requires time and resources

\section{None}

None

Source/s: first author

(year). Full citations are

provided as Online

Supplementary Appendix C

Dykema (2012), Gates

(2009), Jansen (2013),

Kleinpell-Nowell (2000),

Little, Cohen (2012), Meyers

(2003), Sherman (2005)

Dykema (2012), Little, Cohen (2012), Sherman (2005),

Hellard (2001)

Hellard (2001), Little, Cohen (2012), Senturia (1998)

Chassany (2002), Jordhoy (2010), Kaasa (1992),

Revicki (2005)

Bernhard, Cella (1998),

Friedman (1998), Ganz

(2007), Gheorghe (2014),

Hahn (1998), Revicki (2005)

Beitz (1996), Taphoorn (2010)

Fallowfield (1998), Jansen

(2013), Pijls-Johannesma

(2005), Simes (1998)

different views about what

constitutes sensitive data.

Some key issues for

particular studies are

considered sensitive, for

example, sexual function

Complicates trial set up and implementation, particularly when using e-PROs

Kaasa (1998),

Kleinpell-Nowell (2000) 


\begin{tabular}{|c|c|c|c|c|c|}
\hline \multicolumn{6}{|l|}{ Category } \\
\hline Design & Topic & Specific recommendation & $\mathrm{N}$ recommendations ${ }^{*}$ & Potential drawbacks & $\begin{array}{l}\text { Source/s: first author } \\
\text { (year). Full citations are } \\
\text { provided as Online } \\
\text { Supplementary Appendix C }\end{array}$ \\
\hline & $\begin{array}{l}\text { Validated measures (these } \\
\text { are likely to be more clinically } \\
\text { relevant and acceptable to } \\
\text { patients) }\end{array}$ & & 6 & None & $\begin{array}{l}\text { Bernhard, Cella (1998), } \\
\text { Blazeby (2003), Fallowfield } \\
\text { (1998), Kaasa (1992), } \\
\text { Siddiqui (2014) }\end{array}$ \\
\hline & Other & $\begin{array}{l}\text { Ordering questionnaire items } \\
\text { chronologically may speed up } \\
\text { completion time and be easier } \\
\text { for patients to complete }\end{array}$ & 1 & $\begin{array}{l}\text { We strongly recommend } \\
\text { that researchers do not } \\
\text { change the item order of } \\
\text { validated questionnaires. } \\
\text { Questionnaires should be } \\
\text { administered in the exact } \\
\text { format as validated. }\end{array}$ & Dunn (2003) \\
\hline & & $\begin{array}{l}\text { Strategies for measuring } \\
\text { sensitive issues (please see } \\
\text { Chassany } 2002 \text { for a } \\
\text { description of various } \\
\text { strategies) }\end{array}$ & 1 & None & Chassany (2002) \\
\hline \multirow[t]{5}{*}{$\begin{array}{l}\text { PROs part of trial/ } \\
\text { larger study }\end{array}$} & $\begin{array}{l}\text { Research team should commit } \\
\text { to the PRO substudy (eg, } \\
\text { when part of larger trial) }\end{array}$ & & 11 & $\begin{array}{l}\text { Requires time and } \\
\text { resources }\end{array}$ & $\begin{array}{l}\text { Bernhard, Cella (1998), } \\
\text { Bernhard, Peterson (1998), } \\
\text { Cella (1994), Cella (1995), } \\
\text { Chassany (2002), Hayden } \\
\text { (1993), Kiebert (1998), } \\
\text { Moynihan (1998) }\end{array}$ \\
\hline & $\begin{array}{l}\text { Incorporate PROs in trial/main } \\
\text { study design }\end{array}$ & $\begin{array}{l}\text { PROs should be a mandatory/ } \\
\text { integral part of the trial/ larger } \\
\text { study (ie, PRO data are not an } \\
\text { optional extra) }\end{array}$ & 10 & None & $\begin{array}{l}\text { Aaronson (1990), Bernhard, } \\
\text { Cella (1998), Hayden (1993), } \\
\text { Hurny (1992), Kaasa (1992), } \\
\text { Movsas (2004), Osoba } \\
\text { (2007), Sadura (1992), } \\
\text { Siddiqui (2014), Young, de } \\
\text { Haes (1999) }\end{array}$ \\
\hline & & $\begin{array}{l}\text { Consider logistic factors when } \\
\text { designing PRO study }\end{array}$ & 4 & None & $\begin{array}{l}\text { Chassany (2002), Little, } \\
\text { D’Agostino (2012), } \\
\text { Wisniewski (2006), Young, } \\
\text { de Haes (1999) }\end{array}$ \\
\hline & $\begin{array}{l}\text { PRO content in the study } \\
\text { protocol }^{60} 6163\end{array}$ & $\begin{array}{l}\text { Define end points/hypotheses } \\
\text { (ensure PRO end point is } \\
\text { scientifically compelling) }\end{array}$ & 5 & None & $\begin{array}{l}\text { Cella (1994), Fallowfield } \\
\text { (2005), Little, Cohen (2012), } \\
\text { Taphoorn (2010), Walker } \\
\text { (2003) }\end{array}$ \\
\hline & & $\begin{array}{l}\text { Specify how missing data will } \\
\text { be handled }\end{array}$ & 1 & $\begin{array}{l}\text { May not be possible to } \\
\text { fully plan how missing data }\end{array}$ & Calvert (2004) \\
\hline
\end{tabular}




\begin{tabular}{|c|c|c|c|c|c|}
\hline & & & & $\begin{array}{l}\text { will be handled } \\
\text { prospectively }\end{array}$ & \\
\hline & & $\begin{array}{l}\text { Specify the importance of } \\
\text { PRO assessment compliance }\end{array}$ & 1 & None & Fayers (1997) \\
\hline & & $\begin{array}{l}\text { Include/plan PRO aspects of } \\
\text { the study carefully }\end{array}$ & 13 & None & $\begin{array}{l}\text { Bell (2014), Fayers (1997), } \\
\text { Ganz (2007), Hahn (1998), } \\
\text { Hao (2010), Land (2007), } \\
\text { Moinpour (1998), Movsas } \\
\text { (2003), Poy (1993), Revicki } \\
\text { (2005), Sloan (2007),Walker } \\
\text { (2003) }\end{array}$ \\
\hline & & $\begin{array}{l}\text { Specify plans for minimising } \\
\text { missing data (such as those } \\
\text { listed in this review) in the } \\
\text { protocol }\end{array}$ & 11 & None & $\begin{array}{l}\text { Beitz (1996), BIQSFP (2012), } \\
\text { Calvert (2004), Fairclough } \\
\text { (2010), Kaasa (1998), } \\
\text { Moinpour (1998), Revicki } \\
\text { (2005), Simes (1998), Young, } \\
\text { de Haes (1999) }\end{array}$ \\
\hline & & $\begin{array}{l}\text { Specify PRO assessment } \\
\text { schedule }\end{array}$ & 2 & None & $\begin{array}{l}\text { Hopwood (1996), Moinpour } \\
\text { (1998) }\end{array}$ \\
\hline & & $\begin{array}{l}\text { Specify the rationale for PRO } \\
\text { assessment (understanding } \\
\text { why PROs are being } \\
\text { measured and the value the } \\
\text { information will bring to the } \\
\text { trial is useful for all members } \\
\text { of the trial team, and } \\
\text { reinforces the importance of } \\
\text { high-quality PRO data } \\
\text { collection) }\end{array}$ & 11 & None & $\begin{array}{l}\text { Aaronson (1990), Bell (2014), } \\
\text { Cella (1994), Cella (1995), } \\
\text { Conroy (2003), Fayers } \\
\text { (1997), Hopwood (1998), } \\
\text { Sadura (1992) }\end{array}$ \\
\hline $\begin{array}{l}\text { Include PROs in } \\
\text { the SAP } †\end{array}$ & $\begin{array}{l}\text { Specify potential problems } \\
\text { with PRO analysis in SAP }\end{array}$ & & 2 & $\begin{array}{l}\text { May not be possible to } \\
\text { predict and prepare for all } \\
\text { potential problems with } \\
\text { PRO analysis when } \\
\text { developing the SAP }\end{array}$ & $\begin{array}{l}\text { Taphoorn (2010), Walker } \\
\text { (2003) }\end{array}$ \\
\hline & $\begin{array}{l}\text { Plans for addressing missing } \\
\text { data in SAP }\end{array}$ & & 2 & $\begin{array}{l}\text { May not be possible to } \\
\text { fully plan how missing data } \\
\text { will be handled } \\
\text { prospectively }\end{array}$ & $\begin{array}{l}\text { Bell (2014), Bernhard, } \\
\text { Peterson (1998) }\end{array}$ \\
\hline & $\begin{array}{l}\text { PROs in other trial/study } \\
\text { documents }\end{array}$ & & 1 & None & Land (2007) \\
\hline
\end{tabular}


Design Topic

QA-planning ahead

QA

Sample (for PRO

data collection)
PRO subsample (if study power permits and if the study budget or logistics limit capacity to collect PROs from

all participants, consider

collecting PROs from a subsample only)

\section{Specific recommendation}

$\mathrm{N}$ recommendations

Pot

Include PRO study in relevant

sections of procedural

documents

Consider logistic factors when designing PRO study

Create study databases with

QA in mind (ie, consider how

PRO data completion rates will

be monitored using the

database)

Manage PROs with other trial/

study end point data (ie, in a

single database)

Describe QA procedures in

protocol

Specify QA procedures in a

manual

Establish target PRO

compliance rates (ie, quotas

that must be achieved, eg, a

target of $95 \%$ indicates that no

more than $5 \%$ of missing PRO

questionnaires will be

tolerated)

PRO data from representative

subsample of the trial

population

3

2

6

Do not collect PROs from 1

patients with advanced

disease

Allow patients/sites to opt in to the PRO study

Source/s: first author (year). Full citations are

provided as Online

Supplementary Appendix C

\section{5}

2

Data managers will require additional training for PROs-which requires additional time and resources

None

None

None

May be difficult

administratively,

particularly for site staff to implement

QOL issues are often of very important in patients with advanced disease.

\section{Fallowfield (2005)}

Bernhard, Cella (1998), Land (2007), Moinpour (1998),

Wisniewski (2006)

Bernhard, Peterson (1998), Hurny (1992)

Cella (1995), Gheorghe

(2014), Revicki (2005)

Cella (1994),Cella (1995)

Hahn (1998), Little, Cohen (2012), Little, D'Agostino (2012), McMillan (2003), Sloan (2007)

Simes (1998)

Bernhard, Cella (1998)

Simes (1998) 
Recruit motivated patients

only

Bernhard, Cella

(1998), Simes

(1998)

Sample size

Involve committees (to review PRO study)

protocol

development
Separate (additional) consent for PRO study

Increase sample size to allow

for attrition
1

7
Ethics review

PRO committee (ie, some trials groups have a dedicated PRO committee, comprised of PRO research specialists who review and provide feedback on PRO aspects of trials)
May lead to selection bias

if sites or participants

opt-in to PRO study

May also lead to

impression that PRO study

is of lesser importance

than other study outcomes

Requires additional time and resources

The rate of missing data is important, regardless of whether the available data meet sample size

requirements. Although

increasing sample size will improve study power in the case of low PRO

completion rates, the

outcomes of participants with missing PRO data may differ to those with complete PRO data-

which may lead to bias.

None

Requires access to a trials group with resources for a PRO committee
Movsas (2003)

May lead to selection bias if only motivated participants take part in PRO study

Simes (1998)

Altman (2007), Kaasa (2002) ittle, D'Agostino (2012),

Sherman (2005), Stewart (1992), Tang (2002), Jordhoy (2010)

Hahn (1998), Osoba (1992), Osoba (2007), Revicki (2005) 


\section{Design} Topic

Multidisciplinary team involved in design/protocol

Specific recommendation

$\mathrm{N}$ recommendations

development (each party

brings unique and

complementary expertise and

experiences to improve the design of the PRO study)

Involve experienced

investigators in PRO study

design (to offer strategies for

maximising compliance,

selection of informative

measures and time points,

and other key aspects of study

design)

Involve nurses in PRO study

design (to offer expertise

about patient experiences and

relevant $\mathrm{QOL}$ issues, clinic

environment, data collection,

etc)

Involve patients in PRO study

design (to comment on the

acceptability and relevance of

PRO questionnaires, suitability

of assessment time points in

capturing desired outcomes,

patient burden, strategies to

educate and engage

participants, and many othe

important aspect of study

design)

Involve PRO experts in PRO

study design (to offer

\section{None}

2

None

None

None

strategies for maximising

compliance, selection of

informative measures and time

points, analysis and

interpretation strategies and provided as Online

Supplementary Appendix C

Bernhard, Cella (1998), Cella

(1994), Cella (1995), Kiebert

(1998), Moinpour (1998)

Little, Cohen (2012), Little,

D’Agostino (2012)

Hayden (1993)

Bernhard, Peterson (1998), Hurny (1992), Moynihan (1998)

Fallowfield (1998), Kiebert (1998), Basch (2014) 


\begin{tabular}{|c|c|c|c|c|c|}
\hline \multicolumn{6}{|c|}{ Category } \\
\hline \multirow[t]{4}{*}{ Design } & Topic & Specific recommendation & N recommendations* & Potential drawbacks & $\begin{array}{l}\text { Source/s: first author } \\
\text { (year). Full citations are } \\
\text { provided as Online } \\
\text { Supplementary Appendix C }\end{array}$ \\
\hline & & $\begin{array}{l}\text { other key aspects of study } \\
\text { design) }\end{array}$ & & & \\
\hline & & $\begin{array}{l}\text { Involve site coordinators in } \\
\text { PRO study design (to offer } \\
\text { expertise about logistics of } \\
\text { PRO assessment, patient } \\
\text { experiences and relevant QOL } \\
\text { issues, data collection } \\
\text { strategies, etc) }\end{array}$ & 4 & None & $\begin{array}{l}\text { Bernhard, Cella (1998), } \\
\text { Hayden (1993), Larkin } \\
\text { (2012), Moinpour (1998), } \\
\text { Cella (1995) }\end{array}$ \\
\hline & Support the site staff & $\begin{array}{l}\text { Minimise institution/staff } \\
\text { burden (an overly burdensome } \\
\text { PRO assessment schedule or } \\
\text { procedure for site staff is likely } \\
\text { to lead to high rates of missing } \\
\text { data) }\end{array}$ & 6 & None & $\begin{array}{l}\text { Aaronson (1990), Young, de } \\
\text { Haes (1999) }\end{array}$ \\
\hline
\end{tabular}




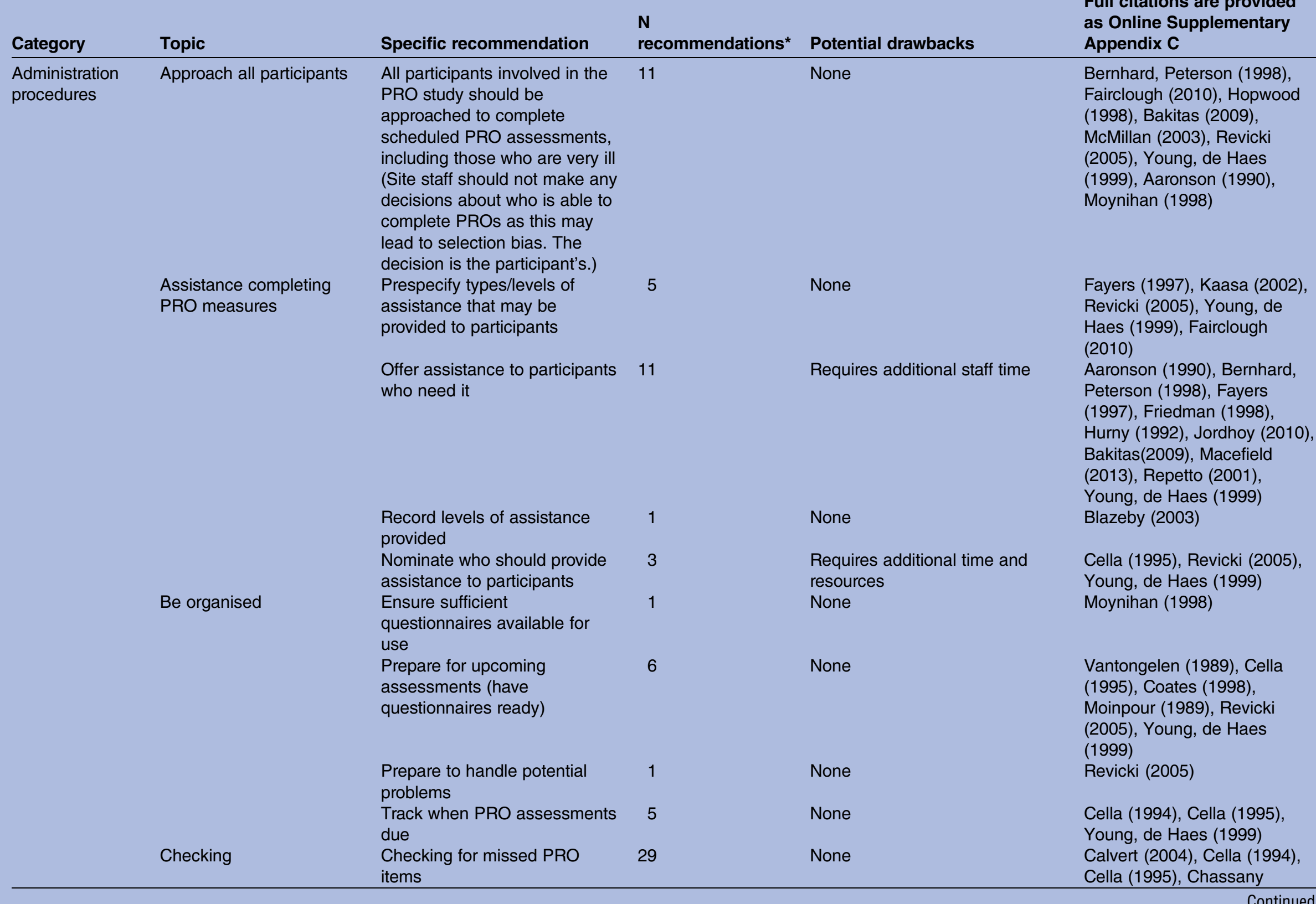


Source/s: first author (year)

N

Category Topic

Specific recommendation

recommendations

Potential drawbacks

Checking source data (data

entry; when entering

questionnaire data into

database)

Ensure patients receive

questionnaires (particularly

when the patients complete

questionnaires outside of

clinic)

PRO completion cover sheet (a form on which site staff can record whether PROs were completed and if not completed, the possible reason why)

Standardised reasons for missing data (possible reasons for non-completion of PROs

may be listed on a cover sheet for the convenience of site staff and for ease of data collection)
2

None

None

None

Requires additional time and resources to collect

Requires additional time and resources to collect

Reasons for missing PRO data may not be easy to determine in some cases.
Full citations are provided

as Online Supplementary

Appendix C

(2002), Davies (1994),

Fallowfield (1998), Fayers

(1997), Fowler (1996),

Friedman (1998), Ganz

(1988), Hayden (1993),

Hopwood (1998),

Kleinpell-Nowell (2000), Kyte

(2013), Moinpour (1990),

Moinpour (1998), Movsas

(2003), Movsas (2004),

Revicki (2005), Taphoorn

(2010), Wisniewski (2006),

Young, de Haes (1999)

Davies (1994), Poy (1993)

Kaasa (1998)

Moinpour (1998)

Fayers (1997), Fairclough (2010), Fayers (1997),

Moinpour (1998), Hopwood

(1998), Revicki (2005)

Fairclough (2010), Fayers

(1997), Moinpour (1998),

Hopwood (1998), Revicki

(2005), Bell (2014), Bernhard,

Cella (1998), Blazeby (2003),

Calvert (2004), Curran (1998), 


\section{N}

Category Topic

Specific recommendation recommendations ${ }^{\star}$ Potential drawbacks
Source/s: first author (year). Full citations are provided as Online Supplementary Appendix C

Fairclough (2010), Fallowfield (1998), Fayers (1997), Hahn (1998), Hao (2010), Kiebert

(1998), Kleinpell-Nowell (2000), Land (2007), Little, Cohen (2012), Luo (2008), Moinpour (1990), Moinpour (1998), Revicki (2005), Simes (1998), Taphoorn (2010), Walker (2003), Wisniewski (2006), Young, de Haes (1999)
Missed assessments

Specify place of PRO in the clinic)

Returning questionnaires completion (eg, quiet spot

\section{Alternative mode of} administration (if participants miss a PRO assessment, contact the participant to capture the data using an alternative mode. Also see table 2 'Mode of administration')

Following up missed assessments
17

Specify procedures for returning questionnaires
Requires additional staff time and resources. Potential for bias based on setting of completion (systematic differences between modes, particularly if one mode is interview administered, and the other is completed by patient ${ }^{66}$ )

Requires additional staff time and resources

May be difficult to offer a quiet place to complete questionnaires in busy clinic environment

None
Basch (2014) Calvert (2004), Cella (1995), Fairclough (2010), Fowler (1996), Hopwood (1996), Hurny (1992), Kleinpell-Nowell (2000), Land (2007), Moinpour (1990), Revicki (2005), Stewart (1992), Walker (2003), Revicki (2005) Cella (1994), Cella (1995), Conroy (2003), Fowler (1996) Hopwood (1998), Huntington (2005), Kleinpell-Nowell (2000), Movsas (2003), Movsas (2004), Sherman (2005), Sprague (2003), Sprangers (2002), Taphoorn (2010), Wisniewski (2006), Young, de Haes (1999)

Calvert (2004), Hurny (1992), Jansen (2013), Moynihan (1998), Sadura (1992), Sherman (2005), Young, de Haes (1999)

Poulter (1997) 
Source/s: first author (year)

\begin{tabular}{|c|c|c|c|c|c|}
\hline Category & Topic & Specific recommendation & $\begin{array}{l}\mathbf{N} \\
\text { recommendations* }\end{array}$ & Potential drawbacks & $\begin{array}{l}\text { Source/s: first author (year). } \\
\text { Full citations are provided } \\
\text { as Online Supplementary } \\
\text { Appendix C }\end{array}$ \\
\hline & \multirow[t]{2}{*}{ Time of completion } & $\begin{array}{l}\text { Standardise time of completion } \\
\text { (eg, first thing when the patient } \\
\text { arrives at the clinic) }\end{array}$ & 2 & None & $\begin{array}{l}\text { Bernhard, Cella (1998), } \\
\text { Fayers (1997) }\end{array}$ \\
\hline & & $\begin{array}{l}\text { Before seeing clinician (many } \\
\text { sources recommended PROs } \\
\text { should be completed before } \\
\text { the participants have their } \\
\text { appointment with their } \\
\text { clinician) }\end{array}$ & 4 & $\begin{array}{l}\text { Requires advanced planning and } \\
\text { potential negotiation with clinician } \\
\text { to ensure PRO assessment is } \\
\text { complete prior to the clinic } \\
\text { appointment. Difficulties may } \\
\text { arise if scheduled PRO } \\
\text { assessments do not align with } \\
\text { clinic visits. }\end{array}$ & $\begin{array}{l}\text { Fayers (1997), Sprague } \\
\text { (2003), Young, de Haes } \\
\text { (1999), Hopwood (1998) }\end{array}$ \\
\hline & \multirow[t]{3}{*}{ Standardised methods } & $\begin{array}{l}\text { Adhere to PRO assessment } \\
\text { schedule }\end{array}$ & 2 & None & $\begin{array}{l}\text { Moinpour (1998), Poulter } \\
\text { (1997) }\end{array}$ \\
\hline & & $\begin{array}{l}\text { Use standard administration } \\
\text { methods }\end{array}$ & 5 & None & $\begin{array}{l}\text { Cella (1995), Chassany } \\
\text { (2002), Movsas (2003), } \\
\text { Movsas (2004), Revicki } \\
(2005)\end{array}$ \\
\hline & & $\begin{array}{l}\text { Standardise methods (eg, by } \\
\text { developing written guidance) }\end{array}$ & 13 & $\begin{array}{l}\text { Time and minimal costs involved } \\
\text { initially }\end{array}$ & $\begin{array}{l}\text { Bernhard, Gusset (1998), } \\
\text { Cella (1995), Chassany } \\
\text { (2002), Fayers (1997), } \\
\text { Gheorghe (2014), Hopwood } \\
\text { (1998), Moinpour (1998), } \\
\text { Movsas (2003), Movsas } \\
\text { (2004), Osoba (2007), Poy } \\
\text { (1993), Revicki (2005), } \\
\text { Sadura (1992) }\end{array}$ \\
\hline & \multirow[t]{3}{*}{ Thank the participant } & $\begin{array}{l}\text { On completion of questionnaire } \\
\text { (face-to-face) }\end{array}$ & 6 & None & $\begin{array}{l}\text { Calvert (2004), Kyte (2013), } \\
\text { Meyers (2003), Sherman } \\
\text { (2005), Steinhauser (2006), } \\
\text { Young, de Haes (1999) }\end{array}$ \\
\hline & & Thank you letters & 3 & $\begin{array}{l}\text { Requires additional time and } \\
\text { resources }\end{array}$ & $\begin{array}{l}\text { Steinhauser (2006), } \\
\text { Fallowfield (1998), Poulter } \\
\text { (1997) }\end{array}$ \\
\hline & & Train staff & - & - & See 'Train staff' category \\
\hline $\begin{array}{l}\text { Participant } \\
\text { education and } \\
\text { engagement }\end{array}$ & Confidentiality & $\begin{array}{l}\text { Be mindful of sensitive PRO } \\
\text { data (ensure participants } \\
\text { understand it will be kept } \\
\text { confidential) }\end{array}$ & 2 & None & Cella (1994), Sherman (2005) \\
\hline
\end{tabular}




\begin{tabular}{|c|c|c|c|c|c|}
\hline Category & Topic & Specific recommendation & $\begin{array}{l}\mathbf{N} \\
\text { recommendations* }\end{array}$ & Potential drawbacks & $\begin{array}{l}\text { Source/s: first author (year). } \\
\text { Full citations are provided } \\
\text { as Online Supplementary } \\
\text { Appendix C }\end{array}$ \\
\hline & \multirow{10}{*}{$\begin{array}{l}\text { Strategies for continued } \\
\text { participant engagement }\end{array}$} & $\begin{array}{l}\text { Discuss family involvement } \\
\text { (participants may not wish to } \\
\text { disclose certain information if } \\
\text { they believe family members } \\
\text { may see the data) }\end{array}$ & 1 & None & Sherman (2005) \\
\hline & & $\begin{array}{l}\text { Inform participants that PRO } \\
\text { data are kept confidential }\end{array}$ & 6 & None & $\begin{array}{l}\text { Calvert (2004), Fallowfield } \\
\text { (1998), Movsas (2003), } \\
\text { Sherman (2005), Simes } \\
\text { (1998), Young, de Haes } \\
\text { (1999) }\end{array}$ \\
\hline & & $\begin{array}{l}\text { Sealed envelopes (allow } \\
\text { participants to self-seal so they } \\
\text { are assured of the } \\
\text { confidentiality of data) }\end{array}$ & 1 & $\begin{array}{l}\text { Prevents site staff from being } \\
\text { able to check for any missing } \\
\text { items }\end{array}$ & Fallowfield (1998) \\
\hline & & $\begin{array}{l}\text { Site staff should offer to } \\
\text { answer participant questions }\end{array}$ & 3 & None & $\begin{array}{l}\text { Calvert (2004), Fayers (1997), } \\
\text { Hurny (1992) }\end{array}$ \\
\hline & & $\begin{array}{l}\text { Awareness of culturally } \\
\text { sensitive issues }\end{array}$ & 1 & None & Bernhard, Cella (1998) \\
\hline & & $\begin{array}{l}\text { Match staff to participant } \\
\text { cultural group (Some } \\
\text { participants may build rapport } \\
\text { more easily if they liaise with a } \\
\text { coordinator from the same } \\
\text { cultural group.) }\end{array}$ & 1 & $\begin{array}{l}\text { May not be possible/feasible for } \\
\text { all studies }\end{array}$ & Cella (1995) \\
\hline & & Build rapport with participants & 4 & None & $\begin{array}{l}\text { Blazeby (2003), Steinhauser } \\
\text { (2006) }\end{array}$ \\
\hline & & $\begin{array}{l}\text { Educate participants about } \\
\text { PROs (importance of PROs, } \\
\text { how PRO data are used, how } \\
\text { to complete PROs) }\end{array}$ & 5 & $\begin{array}{l}\text { Requires staff time and } \\
\text { commitment-depending on the } \\
\text { comprehensiveness of education } \\
\text { offered }\end{array}$ & $\begin{array}{l}\text { Basch (2012), Fairclough } \\
\text { (2010), Gotay (2005), } \\
\text { Huntington (2005), Kaasa } \\
\text { (1998) }\end{array}$ \\
\hline & & $\begin{array}{l}\text { Provide clear/simple } \\
\text { instructions for completion of } \\
\text { PRO assessments }\end{array}$ & 5 & None & $\begin{array}{l}\text { Bernhard, Peterson (1998), } \\
\text { Calvert (2004), Chassany } \\
\text { (2002), Hurny (1992), Revicki } \\
\text { (2005) }\end{array}$ \\
\hline & & $\begin{array}{l}\text { Encourage participants to ask } \\
\text { for questionnaire when they } \\
\text { are due (in case site staff } \\
\text { forget) }\end{array}$ & 2 & None & $\begin{array}{l}\text { Fayers (1997), Hopwood } \\
\text { (1998) }\end{array}$ \\
\hline
\end{tabular}



Category Topic Specific recommendation

Category

recommendations* Potential drawbacks

Ensure participants understand

8

(PRO assessment/how to

complete questionnaires, etc)

Collect information about

4

participants at risk of dropping

out and use that information to

intervene, or implement

intensive follow-up strategies

for these participants

Maintain contact with

participants

Send participants PRO

assessment reminders

Provide assistance to

participants when required

Provide encouragement to

participants when completing

PROs

Explain reason for multiple

PRO assessments

Explain and remind

participants of importance of

PROs

Update participants on trial/ study progress
Source/s: first author (year). Full citations are provided as Online Supplementary Appendix C

Moinpour (1990), Moinpour (1998), Muller-Buh (2011), Poulter (1997), Revicki (2005)

Little, D'Agostino (2012),

Risk of drop out may be difficult to predict in some samples.

Senturia (1998),Sprague (2003)

Requires staff time, resources and commitment

Requires staff time, resources and commitment

Requires staff time, resources and commitment

Requires staff time, resources and commitment

None

None

Requires staff time, resources and commitment
Hellard (2001),

Kleinpell-Nowell (2000),

Senturia (1998), Wisniewski (2006)

Altman (1993), Basch (2012),

Bell (2014), Bernhard, Cella

(1994), Cella (1995), Cella

(1998), Fallowfield (1998),

Jansen (2013),

Kleinpell-Nowell (2000), Land

(2007), Revicki (2005),

Sherman (2005), Sprague

(2003), Wisniewski (2006)

Fairclough (2010)

Basch (2012), Bernhard, Cella (1998), Little, Cohen (2012),

Revicki (2005)

Bernhard, Peterson (1998),

Calvert (2004), Hurny (1992),

Sprague (2003)

Fayers (1997), Kyte (2013)

Taphoorn (2010), Wilcox

(2001), Calvert (2004), Cella

(1995), Chassany (2002),

Conroy (2003), Hellard

(2001), Sherman (2005)

Cella (1995), Hellard (2001)

Little, Cohen (2012), Sadura (1992) 


\section{Category} Topic

Informed consent (ensure these aspects of PRO study are addressed)

Explain importance of complete PRO data

Explain that participation is voluntary

Language translations

available (participants may fee

more confident using an

alternative language translation

that the default language

offered)

Ensure participant understands
N

recommendations* Potential drawbacks

None

None

None

None

None

14

5

None

None

None

None
Source/s: first author (year). Full citations are provided

as Online Supplementary

Appendix C

Young T, de Haes (1999)

Young T, de Haes (1999)

Bernhard, Cella (1998), Blazeby (2003), Hurny (1992), Sherman (2005), Sprague

(2003), Young, de Haes

(1999)

Fallowfield (1998), Fayers

(1997), Hopwood (1998),

Movsas (2003), Moynihan

(1998)

Bernhard, Cella (1998),

Conroy (2003), Fairclough

(2010), Fayers (1997),

Friedman (1998), Hurny

(1992), Kleinpell-Nowell

(2000), Blazeby (2003),

Revicki (2005),Taphoorn

(2010), Walker (2003), Young,

de Haes (1999)

Bernhard, Peterson (1998),

Little, Cohen (2012), Young T,

de Haes (1999),

Kleinpell-Nowell (2000),

Revicki (2005)

Sherman (2005)

Young T, de Haes (1999)

Ganz (1988), Young, de Haes (1999) 
Source/s: first author (year).
Full citations are provided Category Topic Specific recommendation

\section{recon}

Participants can take

information sheets home.

Recruitment method

Face-to-face recruitment

Follow the recruitment protocol

Less aggressive recruitment 2

methods may be more

effective than more assertive methods.

Participant Obtain contact details at records registration

Specify procedures for checking and updating participant records

Update participant records Check if participant is alive (It may be distressing for friends/ family members if study

reminder letters are posted to participants home after they have died. This situation can

be avoided by contacting the participant's doctor for updates on the participant's condition.)

Update participant contact details

Record successful strategies for contacting participants (so that these strategies may be used for future study contact) as Online Supplementary

Appendix C

Fayers (1997), Land (2007)

None

None

None

Jansen (2013)

Senturia (1998)

May result in reduced

recruitment. Recruitment method

should not be aggressive, not

lax.

Some participants may not have a trusted friend/relative to nominate as alternate contact.

Alternate contact person will need to provide consent to be contacted-which may be difficult to obtain and/or implement.

Participant contact details may change during the course of the study; therefore, contact details should be checked regularly. None

Must be handled carefully if participants' relatives are contacted, and may require formal approval if participants' GPs are contacted

Requires time and resources

None (1990), Senturia (1998)

Kleinpell-Nowell (2000),

Senturia (1998), Sherman (2005)

Sprague (2003)

Fallowfield (1998), Hopwood (1996)

Kleinpell-Nowell (2000), Little, Cohen (2012), Little, D'Agostino (2012), Meyers

(2003), Young, de Haes (1999)

Meyers (2003) 


\section{Category}

Quality

assurance

Topic

Specific recommendation

Central office monitors

compliance

Appoint a central PRO coordinator/QA officer

Real-time monitoring of PRO completion (enables prompt intervention if PRO assessments are missed)

\section{Communication}

Central monitors should discuss participants who withdraw with site staff (this may identify potential issues with site management and

potential strategies for avoiding problems in future).

Discuss the role of site staff in responding to participants' medical needs

Central office should send

feedback reports to sites on

PRO compliance and reasons

for missing PRO data (this may assist sites to recognise problematic patterns in missing

\section{N}

recommendations* Potential drawbacks

Requires planning and resources to implement

Requires additional resources

Requires time, commitment and resources of site and central monitoring staff. Requires input from database developers and statisticians from set-up phase. Difficult to implement for multisite trials due to delays in obtaining

PRO forms from sites, and differences between patients in recruitment time

Requires real-time compliance monitoring, which requires time, commitment and resources of central and site staff

None

Requires real-time compliance monitoring, which requires time and resources of central staff
Source/s: first author (year). Full citations are provided as Online Supplementary Appendix C

Bernhard, Cella (1998) Hayden (1993), Kiebert (1998), Land (2007)

Bell (2014), Bernhard, Cella (1998), Cella (1994), Cella (1995), Fallowfield (1998), Hahn (1998), Hurny (1992), Land (2007), Moinpour (1990), Poy (1993), Simes (1998), Sloan (2007) Basch (2012), Basch (2014), Bernhard, Cella (1998), Bernhard, Gusset (1998), Bernhard, Peterson (1998), Ganz (2007), Hayden (1993), Huntington (2005), Kyte (2013), Little, Cohen (2012) Movsas (2003), Poy (1993) Revicki (2005), Siddiqui (2014), Sprague (2003)

Walker (2003), Wilcox (2001), Wisniewski (2006), Young, de Haes (1999) Sprague (2003)

Sherman (2005)

Bernhard, Peterson (1998), Bernhard, Cella (1998), Land (2007), Friedman (1998), Hahn (1998), Hurny (1992), Senturia (1998), Wilcox 
Source/s: first author (year)

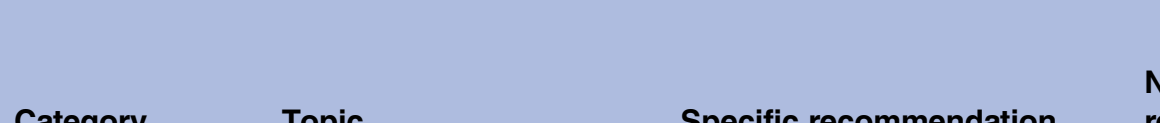

Category Topic

Specific recommendation

data, and to work towards

rectifying such issues).

Sites should send feedback to

central office (problems

participant feedback, etc,

which may be able to be

addressed through discussion,

in future protocol amendments

or in future studies)

Importance of regular

communication between

research team

Regular meetings (a forum for communication between the research team)

Share strategies for successful PRO compliance

Schedule when reports are due for the sites to communicate

with the central office

Reward high performing sites/staff

Document methods of success

(regarding high PRO

completion rates)

Offer financial incentives to

sites for high completion rates

Offer incentives to sites for

high completion rates (type of

incentive unspecified)

Offer National Cancer Institute

( $\mathrm{NCl}, \mathrm{USA})$ credit as incentive

\section{recommendations* Potential drawbacks}

Time commitment

Full citations are provided

as Online Supplementary

Appendix C

(2001), Young, de Haes

(1999), Young, Maher (1999)

Bernhard, Gusset (1998)

Hopwood (1998)

Requires time and resources

Requires time and resources

None

None

None

Costs involved

Costs involved

Costs involved Calvert (2004), Cella (1994),

Cella (1995), Hayden (1993),

Land (2007), Moinpour

(1998), Moynihan (1998),

Osoba (1992), Poy (1993),

Wisniewski (2006), Young, de Haes (1999)

Cella (1994), Land (2007)

Moinpour (1989), Osoba

(1996), Sprague (2003)

Wisniewski (2006)

Bernhard, Peterson (1998),

Calvert (2004),

Kleinpell-Nowell (2000)

Cella (1995)

Stewart (1992)

Little, D'Agostino (2012),

Ganz (2007), Little, Cohen

(2012), Aaronson (1990),

Bernhard, Gusset (1998)

Basch (2012), Bernhard, Cella

(1998), Cella (1995), Hurny

(1992)

Land (2007) 
Topic

Poorly performing sites

QA should be in place to promote high completion rates

Rate site's performance and assess against benchmark compliance

rates

Site-level monitoring

Support for sites/staff

\section{Specific recommendation}

Offer non-financial incentives

Site coordinator authorship as incentive

Thank you letters to site staff

Travel support to high

performing site staff as

incentive

Intervene in poorly performing

sites (ie, with additional

training, discussion about

support needed to improve

completion rates, etc)

Introduce incentives if

improvement is seen at poorly

performing sites

Penalise sites for poor

compliance (eg, eliminate

opportunity for future

recruitment/involvement in

future trials)

Terminate recruitment at poorly

performing sites

recommendations* Potential drawbacks

Costs involved

Costs involved

Time and costs involved

Costs involved

Source/s: first author (year)

Full citations are provided

as Online Supplementary

Appendix C

Little, D’Agostino (2012)

Moinpour (1998)

Land (2007)

Hahn (1998)

Requires real-time compliance monitoring, and time and resources to implement interventions

Costs involved. Need to be introduced before compliance rates fall too low.

May reduce morale at that site if not handled appropriately

\section{(B)}

Hayden (1993), Land (2007),

Moinpour (1998)

May reduce number of patients eligible for recruitment

Requires commitment and

resources to implement

Requires real-time compliance monitoring, which requires centra staff time and resources

Requires time and commitment of Poy (1993)

site and central staff

Requires time and resources

Hahn (1998)

Sites should also monitor their

own compliance rates

Offer ongoing training to site staff 
Source/s: first author (year). Full citations are provided

\section{Category} Topic

\section{Specific recommendation}

Send site staff reminders (for assessments) upcoming/overdue PRO

recommendations* Potential drawbacks -an individual at each site responsible for $\mathrm{PRO}$ administration for the study
Requires time and resources

Site coordinato
Roving coordinator (Rural/ remote centres may have too few participants to warrant appointing a dedicated site coordinator. Instead a roving coordinator may be responsible for several such sites.)

Nominate a back-up site coordinator (If a primary site coordinator is absent, this
Costs involved

May be difficult to implement if rural centres are geographically distant, and if participants have similar PRO assessment schedules

Requires additional resources to ensure back-up coordinator is adequately trained and informed about the PRO study as Online Supplementary Appendix C

Basch (2012), Bernhard, Cella (1998), Bernhard, Peterson (1998), Cella (1994), Cella

(1995), Fairclough (2010), Hahn (1998), Hayden (1993), Hurny (1992), Land (2007),

Moinpour (1989), Moinpour

(1998), Osoba (1992), Poulter (1997), Revicki (2005),

Sadura (1992), Siddiqui (2014), Simes (1998),

Vantongelen (1989)

Beitz (1996), Bernhard, Cella (1998), Bernhard, Peterson (1998), Blazeby (2003),

Calvert (2004), Cella (1994), Cella (1995), Conroy (2003),

Fallowfield (1998), Fayers (1997), Ganz (1988), Gotay (2005), Hahn (1998), Hayden (1993), Hopwood (1998), Hurny (1992), Kaasa (1992), Kyte (2013), Moinpour (1989), Moinpour (1990), Muller-Buh (2011), Poulter (1997), Revicki (2005), Stewart (1992), Young, de Haes (1999)

Scott (2004)

Calvert (2004), Fayers (1997), Revicki (2005) 


\begin{tabular}{|c|c|c|c|c|c|}
\hline Category & Topic & Specific recommendation & $\begin{array}{l}\mathrm{N} \\
\text { recommendations* }\end{array}$ & Potential drawbacks & $\begin{array}{l}\text { Source/s: first author (year). } \\
\text { Full citations are provided } \\
\text { as Online Supplementary } \\
\text { Appendix C }\end{array}$ \\
\hline & & $\begin{array}{l}\text { individual will take } \\
\text { responsibility for the trial.) }\end{array}$ & & & \\
\hline & $\begin{array}{l}\text { Characteristics of site } \\
\text { coordinator }\end{array}$ & Committed to the study & 2 & None & $\begin{array}{l}\text { Blazeby (2003), Larkin (2012), } \\
\text { Moinpour (1998) }\end{array}$ \\
\hline & & $\begin{array}{l}\text { Site staff should be } \\
\text { accommodating/flexible }\end{array}$ & 7 & $\begin{array}{l}\text { The flexibility of site staff is } \\
\text { limited by their individual } \\
\text { schedules and the resources } \\
\text { available at the site }\end{array}$ & $\begin{array}{l}\text { Senturia (1998), Sherman } \\
\text { (2005), Sprague (2003) }\end{array}$ \\
\hline & & Interpersonal skills & 1 & $\begin{array}{l}\text { Interpersonal skills cannot always } \\
\text { be taught }\end{array}$ & Bernhard, Cella (1998) \\
\hline & & $\begin{array}{l}\text { Languages spoken (if the site } \\
\text { has participants from multiple } \\
\text { language backgrounds, it may } \\
\text { be crucial to employ a } \\
\text { coordinator who can speak } \\
\text { these language/s) }\end{array}$ & 1 & $\begin{array}{l}\text { May be difficult to recruit } \\
\text { multilingual site coordinators }\end{array}$ & Bernhard, Peterson (1998) \\
\hline & & Positive attitude & 8 & $\begin{array}{l}\text { Difficult to train staff to have a } \\
\text { positive attitude. Ascertaining } \\
\text { and intervening in such problems } \\
\text { may be difficult to implement. }\end{array}$ & $\begin{array}{l}\text { Bernhard, Cella (1998), } \\
\text { Fairclough (2010), Kaasa } \\
\text { (1992), Larkin (2012), Revicki } \\
\text { (2005), Scott (2004), } \\
\text { Sherman (2005) }\end{array}$ \\
\hline \multirow[t]{4}{*}{$\begin{array}{l}\text { Team involved in } \\
\text { study } \\
\text { implementation }\end{array}$} & $\begin{array}{l}\text { Commitment to the PRO } \\
\text { study-required of the } \\
\text { entire trial team, } \\
\text { specifically: }\end{array}$ & Central office staff & 1 & $\begin{array}{l}\text { May require some education } \\
\text { about the value and importance } \\
\text { of complete PRO data-which } \\
\text { may require additional time and } \\
\text { resources }\end{array}$ & Osoba (2007) \\
\hline & & Physicians & 2 & $\begin{array}{l}\text { May require some education } \\
\text { about the value and importance } \\
\text { of complete PRO data-which } \\
\text { may require additional time and } \\
\text { resources }\end{array}$ & $\begin{array}{l}\text { Hurny (1992), Vantongelen } \\
\text { (1989) }\end{array}$ \\
\hline & & Multidisciplinary support & 2 & $\begin{array}{l}\text { May require some education } \\
\text { about the value and importance } \\
\text { of complete PRO data-which } \\
\text { may require additional time and } \\
\text { resources }\end{array}$ & Poy (1993) \\
\hline & & Site coordinators & 3 & $\begin{array}{l}\text { May require some education } \\
\text { about the value and importance } \\
\text { of complete PRO data-which } \\
\text { may require additional time and } \\
\text { resources }\end{array}$ & Larkin (2012), Hayden (1993) \\
\hline
\end{tabular}




Category Topic Specific recommendation

N

Participants

Sponsor

(group of

PRO experts involved with a

trials group who liaise with and

advise trial investigators about

PRO research. Committees

may review $\mathrm{PRO}$ aspects of

protocols or may be

represented on trial teams ${ }^{69}$ )

Support the site staff

Offer support to sites/staff (eg

psychological support,

bereavement counselling)

Minimise institution burden

Offer a flexible working

environment for site staff

Reward site staff for their work

Training for site coordinators is needed
2

\section{recommendations* Potential drawbacks}

May require some education about the value and importance of complete PRO data-which

may require additional time and resources

May require some education about the value and importance of complete PRO data-which may require additional time and resources

May require additional time and resources

Requires time and resources

None

Needs to be negotiated within the needs of the PRO study

Needs to be negotiated within the resources of the study

Requires time and resources
Train staff Train site staff
Source/s: first author (year).

Full citations are provided

as Online Supplementary

Appendix C

Hayden (1993)

Poy (1993)

Hahn (1998), Osoba (1992)

Wilcox (2001), Sherman (2005), Steinhauser (2006)

Aaronson (1990), Young, de Haes (1999)

Steinhauser (2006)

Steinhauser (2006)

Basch (2012), Bernhard, Cella

(1998), Bernhard, Gusset

(1998), Bernhard, Peterson

(1998), Cella (1995),

Fairclough (2010), Ganz

(2007), Gotay (2005), Hahn

(1998), Hopwood (1998),

Huntington (2005), Hurny

(1992), Movsas (2003),

Movsas (2004), Moynihan

(1998), Osoba (1996), Poulter

(1997), Poy (1993), Revicki

Continued 
N

Category Topic Specific recommendation
Source/s: first author (year). Full citations are provided as Online Supplementary Appendix C

(2005), Sherman (2005), Vantongelen (1989), Walker (2003)

Booster/ongoing training should also be offered, particularly if the trial/study runs over many years and staff changeover is expected.

Poorly performing sitesadditional training should be offered to help improve compliance rates in future

Content of training for trial staff-the following issues related to PROs should be addressed:

(particularly for site

coordinators-good

communication skills are essential for ensuring the PRO

study is explained to

participants, ensuring

participants' questions are

answered, and for building

rapport)

Data cannot be retrieved later (this point should be made at training so that staff

understand the importance of adhering to PRO assessment

time windows)

Good clinical practice/good

research practice

Informed consent (PRO issues

to discuss at consent stage)

Missing PRO data/importance

of compliance
Requires time and resources

Requires central monitoring to identify poorly performing sites +time/resources to implement training

Requires time and resources

Requires time and resources

Requires time and resources

Requires time and resources

Requires time and resources
Cella (1995)

Bernhard, Cella (1998),

Bernhard, Peterson (1998),

Cella (1994), Cella (1995),

Hahn (1998), Larkin (2012),

Moinpour (1998), Revicki

(2005), Wilcox (2001),

Wisniewski (2006), Young, de Haes (1999), Young, Maher (1999)

Fayers (1997), Hopwood (1998), Poy (1993)

Bernhard, Peterson (1998), Moynihan (1998), Poy (1993), Wilcox (2001)

\section{Poy (1993)}

Little, Cohen (2012)

Wisniewski (2006)

Fairclough (2010), Little,

Cohen (2012), Luo (2008), Meyer (2009), Moinpour 
N

Category Topic Specific recommendation

recommendations* Potential drawbacks

Purpose/importance of PRO

assessments

Standardised procedures

(importance of using

standardised methods to

administer PROs to minimise

risk of bias)

Format of training

Informational newsletters (as an additional training format)

Pilot study as a training

exercise in administering PROs and addressing common

problems

Video training (format)

Timing of training

Requisite training for site coordinators (All site

coordinators should receive

training about PROs before

they can work on studies with

PROs.)

Training at the start-up

presentation (which can

address study-specific PRO

issues as well as general PRO

issues)

Train clinician investigators
Source/s: first author (year).

Requires time and resources Full citations are provided as Online Supplementary Appendix C

(1998), Young T, de Haes (1999)

Calvert (2004), Cella (1994)

Cella (1995), Hahn (1998), Hopwood (1998), Little, D’Agostino (2012), Moinpour (1998), Poulter (1997), Taphoorn (2010), Walker (2003), Young, de Haes (1999), Young, Maher (1999) Bernhard, Peterson (1998),

Chassany (2002), Friedman (1998), Hayden (1993), Hurny (1992), Moinpour (1989), Sadura (1992), Sloan (2007) Moinpour (1989)

Requires time and resources Cella (1994)

Requires time, costs and resources

Bernhard, Cella (1998), Hayden (1993), Revicki (2005)

Moinpour (1990), Sadura (1992), Wisniewski (2006)

Requires time and resources

Fallowfield (1998), Fairclough (2010)

Hahn (1998), Aaronson (1990), Poy (1993), Young, de Haes (1999) 


\section{Category \\ Reporting一trial reports enable readers to interpret \\ the possible impact \\ of missing PRO data \\ on findings}

Study power calculation and power achieved for the PRO analysis (Has missing data led to substantial loss of

power for PRO analyses?)

Report analysis methods used

Assumptions of PRO analyses, including assumptions about missing PRO data

How missing PRO data was handled for the analysis

Sensitivity analyses (How has missing data impacted the findings?)
Source/s: first author (year). Full citations are provided as Online

\section{Potential} Supplementary Appendix C

None-however level of detail must be balanced with word limit restrictions.

None-however, level of detail must be balanced with word limit

restrictions.

None-however, level of detail must be balanced with word limit restrictions.

None

Revicki (2007)

1

Revicki (2007)

None-however, level of detail must be balanced with word limit restrictions.

None-however, level of detail provided must be balanced with word limit restrictions. None

None-however level of detail must be balanced with word limit

restrictions. 


\begin{tabular}{|c|c|c|c|c|c|}
\hline Category & Topic & Specific recommendation & $\begin{array}{l}\mathrm{N} \\
\text { recommendations* }\end{array}$ & $\begin{array}{l}\text { Potential } \\
\text { drawbacks }\end{array}$ & $\begin{array}{l}\text { Source/s: first author (year). Full } \\
\text { citations are provided as Online } \\
\text { Supplementary Appendix C }\end{array}$ \\
\hline & \multirow[t]{3}{*}{ Describe the sample } & $\begin{array}{l}\text { Clinical and demographic } \\
\text { characteristics, including } \\
\text { baseline PRO scores }\end{array}$ & 5 & None & $\begin{array}{l}\text { Hewitt (2010), Noyez (2011), } \\
\text { Revicki (2005) }\end{array}$ \\
\hline & & $\begin{array}{l}\text { Compare participants with and } \\
\text { without missing data }\end{array}$ & 4 & $\begin{array}{l}\text { None-however, } \\
\text { level of detail } \\
\text { provided must be } \\
\text { balanced with word } \\
\text { limit restrictions. }\end{array}$ & $\begin{array}{l}\text { Dumville (2006), Hewitt (2010), } \\
\text { Sprangers (2002), Revicki (2005) }\end{array}$ \\
\hline & & $\begin{array}{l}\text { Flow diagram (for PRO study), } \\
\text { including rates and reasons } \\
\text { for non-completion }\end{array}$ & 1 & $\begin{array}{l}\text { None-however, } \\
\text { level of detail must } \\
\text { be balanced with } \\
\text { word limit } \\
\text { restrictions }\end{array}$ & Revicki (2005) \\
\hline & \multirow[t]{4}{*}{ Report missing data details } & $\begin{array}{l}\text { Compliance definitions (What } \\
\text { was considered a missing } \\
\text { response? How was PRO } \\
\text { assessment compliance } \\
\text { measured?) }\end{array}$ & 1 & $\begin{array}{l}\text { None-however, } \\
\text { level of detail must } \\
\text { be balanced with } \\
\text { word limit } \\
\text { restrictions. }\end{array}$ & Lee (2000) \\
\hline & & $\begin{array}{l}\text { Report the expected PRO } \\
\text { completion rate (number of } \\
\text { participants alive and on the } \\
\text { study per time point) }\end{array}$ & 3 & None & $\begin{array}{l}\text { Bernhard (1998), Lee (2000), } \\
\text { Revicki (2007) }\end{array}$ \\
\hline & & $\begin{array}{l}\text { Report rates of missing PRO } \\
\text { data }\end{array}$ & 26 & None & $\begin{array}{l}\text { Bell (2014), Bernhard, Cella (1998), } \\
\text { Calvert (2013), Chassany (2002), } \\
\text { Fallowfield (2005), Flores (2004), } \\
\text { Kaasa (2002), Lee (2000), Luo } \\
\text { (2008), Machin (1998), Noyez } \\
\text { (2011), Revicki (2005), Revicki } \\
\text { (2007), Staquet (1996), Walker } \\
\text { (2003) }\end{array}$ \\
\hline & & $\begin{array}{l}\text { Report reasons for/type of } \\
\text { missing PRO data }\end{array}$ & 15 & $\begin{array}{l}\text { None-however, } \\
\text { level of detail } \\
\text { provided must be } \\
\text { balanced with word } \\
\text { limit restrictions }\end{array}$ & $\begin{array}{l}\text { Bernhard, Cella (1998), Calvert } \\
\text { (2013), Chassany (2002), Deo } \\
\text { (2011), Fallowfield (2005), Flores } \\
\text { (2004), Lee (2000), Macefield } \\
\text { (2013), Machin (1998), Noyez } \\
\text { (2011), Revicki (2007), Sprangers } \\
\text { (2002), Staquet (1996), Walker } \\
\text { (2003) }\end{array}$ \\
\hline & $\begin{array}{l}\text { Potential bias due to } \\
\text { non-response/impact on } \\
\text { generalisability }\end{array}$ & $\begin{array}{l}\text { Authors should consider and } \\
\text { report how missing data } \\
\text { may have impacted the } \\
\text { generalisability of findings. }\end{array}$ & 6 & $\begin{array}{l}\text { None-however, } \\
\text { level of detail must } \\
\text { be balanced with } \\
\text { word limit } \\
\text { restrictions. }\end{array}$ & $\begin{array}{l}\text { Bell (2013), Klee (1999), Machin } \\
\text { (1998), Revicki (2005) }\end{array}$ \\
\hline
\end{tabular}


communication with poorly performing sites led to reductions in rates of missing baseline PROs. Many trial groups have reported success of centralised monitoring systems for maintaining high PRO completion rates. $^{29}$ 35-37

Staff should have access to ongoing training and written guidance, and should understand the importance of PROs. ${ }^{5} 26 \quad 32 \quad 34$ 37-42 The National Cancer Institute of Canada Clinical Trials Group (NCIC CTG) has attributed high PRO completion rates to training the trial team about the importance of avoiding missing PRO data. ${ }^{43}$ Patient engagement is also crucial. Hellard $e t a t^{44}$ found that sending participants' study updates was the primary reason for high-level participant engagement and retention, and weekly study diary completion rates of $90.7 \%$ over 68 weeks. All of these recommendations require intensive resources ${ }^{45} 46$ and research team commitment, ${ }^{47}$ and highlight the importance of conducting appropriate feasibility checks before activating the study. Research investigators, sponsors and funding bodies have a responsibility to ensure research funds are allocated to quality assurance of PRO studies. Training regarding the importance and efficacy of specific quality assurance strategies may be the catalyst to securing such funding.

Rouette $e t a l^{48}$ found that $86 \%$ of clinicians surveyed considered missing data important in interpreting PRO findings, and that clinicians require clear summaries and recommendations for accurate interpretation of trial results. Clear and sufficient information should be reported, so readers can meaningfully interpret the possible impact (bias) of missing PRO data on findings, which is crucial for PROs to impact patient care. This involves reporting descriptions of the study sample, including baseline PRO scores; rates and reasons for missing PRO data; analysis methods, including sensitivity analyses and analysis assumptions, handling of missing data, and discussing the potential impact of missing data on PRO findings. These reporting recommendations are also addressed in the CONsolidated Standards of Reporting Trials (CONSORT) PRO extension, underscoring their importance to transparency of reporting. ${ }^{49}$

Systematic reviews have highlighted that methods for handing missing PRO data are often incorrectly or simply not applied, ${ }^{10}{ }^{14}$ and the extent and handling of missing PRO data is often unreported. ${ }^{8} 10$ 49-51 These omissions may hinder the reader from being able to interpret the impact of missing data on findings. Journal editors should enforce reporting guidance such as CONSORT-PRO ${ }^{49}$ in order to promote and maintain a high standard of research evidence. A recent study found that $31 \%$ of reviewed RCTs failed to report PRO results despite including PRO endpoints in the trial protocol. ${ }^{52}$ The authors could not determine reasons why the RCTs failed to report PROs; however, high rates of missing data have discouraged investigators from publishing PRO findings previously. ${ }^{11}$ This represents a waste of research resources, participants' time and limited research funding as PRO findings left unreported cannot impact patient care. ${ }^{53}$ Trial registration and publication of research protocols is a motion towards avoiding such examples of publication bias; however, further action towards improving the quality of PRO data is needed, beginning with more comprehensive training about PROs for all research staff. Thus, there is an urgent need for research teams to implement the described strategies to minimise missing PRO data and when missing data are present, to reduce its impact on the quality and dissemination of results.

\section{Strengths}

The literature on missing PRO data largely comprises statistically technical material that may be inaccessible for non-statisticians. We have summarised the problems created by missing PRO data in a format accessible to anyone involved in designing, conducting or analysing a clinical study. In response to the need for all members of the research team to assist in minimising the problem of missing data, we have provided the first systematic review to collate practical strategies to minimise the problem of missing PRO data. A comprehensive search strategy was used, developed with assistance from field experts and librarians. The review includes recommendations from a substantially large number of sources from various health disciplines. Many were discussion pieces written by highly regarded and experienced PRO experts based on strategies that their trials group or organisations have implemented, with documented improvement in PRO completion rates. This review, therefore, brings together the collective wisdom of experienced opinion leaders in the field. Further, most recommendations are generalisable across disciplines. Patterns and similarities in the recommendations extracted, as well as emerging findings of ongoing work investigating causes of missing PRO data, ${ }^{54}$ provide evidence of their effectiveness in preventing and addressing the missing PRO data problem.

\section{Limitations}

As the majority of papers included in our systematic review were discussion or guidance pieces rather than original research reports, we were unable to apply study quality criteria used in traditional systematic reviews to the source papers. However, we did consider potential limitations of each recommendation, which is useful information for researchers considering implementing these strategies. Further, we have cited the frequency of each recommendation. High frequency may indicate widespread use and effectiveness, although we do acknowledge that some less-cited strategies may also be highly effective, and some strategies may only apply to specific disease or research contexts. Gathering empirical evidence as to the degree of effectiveness of the strategies identified in this review would be an interesting direction for future research.

Despite our efforts in extensively hand-searching reference lists and citing articles, it is possible that relevant 
sources and/or recommendations were missed. We restricted our database search to MEDLINE and CINAHL databases, and excluded non-English sources. Searching of non-English language databases may have identified additional publications; however, since many themes were identified by numerous sources, we do not believe that this would significantly affect our findings. ${ }^{55}$ Coding of recommendations was a subjective process and, as with all qualitative approaches, is subject to interpretation of the analysts; however, rounds of code checking ensured the original meaning of recommendations was retained as far as possible.

This paper discusses one aspect of PRO data quality: data completeness. Many other factors contribute to highquality PRO data, such as clinical and psychometric appropriateness of PRO measures (valid, reliable, responsive), compliance with time windows, and ensuring that patients self-complete. ${ }^{57}$ Likewise, many factors can contribute to invalid interpretation of PRO data, including multiple hypothesis testing ${ }^{57}$ and clinical versus statistical significance. ${ }^{58}{ }^{59}$ Some of these issues have been addressed in the context of missing data in this review, but are independently crucial PRO assessment concerns. Readers are directed to the following sources for further guidance on PRO study design, ${ }^{57}$ protocol development, ${ }^{60} 61$ analysis $^{1757}$ and reporting ${ }^{4962}$ of PRO studies.

\section{Implications}

We recommend that all members of the research team involved in designing, collecting, analysing and reporting PRO data implement the strategies outlined in this review to minimise the problem of missing PRO data. Missing PRO data are preventable in many cases through rigorous study design and methodology. Further guidance on PROspecific content of trial protocols is required, and is currently under development in the form of a Standard Protocol Items for Clinical Trials (SPIRIT)-PRO extension. ${ }^{63}$ Significant funding, and staff and participant time is invested in PRO studies. Poorly conducted PRO studies with high rates of preventable missing data yield poor quality evidence. Funding organisations and sponsors should actively promote high-quality PRO research by mandating PRO training for research team members, and publication of PRO findings (adhering to CONSORT PRO extension where applicable) to optimise the value of PRO data and avoid research waste. ${ }^{53} 63$

However, we acknowledge that in some health settings, missing PRO data are not avoidable due to deteriorating health status of the participants. We have also outlined strategies that may assist statisticians to appropriately handle unavoidable missing PRO data to minimise bias. Again, transparent and complete reporting of missing PRO data and analysis methods, as described in this review, will promote valid interpretation of PRO findings and assist investigators to make better-informed recommendations for patient care, policy and therapeutic labelling.

\section{CONCLUSION}

It is essential that all researchers involved in design, conduct, analysis and reporting of PRO data appreciate why missing data is a problem, why in many circumstances statistical methods for handling missing data are not failsafe, and how all members of the research team can assist in minimising the problem of missing PRO data, so that misunderstandings do not become a barrier to achieving the highest possible PRO completion rates. To not do so represents a great waste of research resources and valuable PRO evidence. Careful planning of PRO studies can minimise the risk and problem of missing PRO data. Ongoing quality assurance and team commitment throughout study implementation is also essential, which may be facilitated by involvement of PRO experts and sponsors. Despite the existence of missing PRO data, it is possible to make valid conclusions about the effect of disease and treatment on the patient if missing data are appropriately handled and analysed, and transparently reported.

\section{Author affiliations}

${ }^{1}$ Central Clinical School, Sydney Medical School, University of Sydney, Sydney, New South Wales, Australia

${ }^{2}$ Psycho-oncology Co-operative Research Group, School of Psychology, University of Sydney, Sydney, New South Wales, Australia

${ }^{3}$ Department of Cancer Care and Epidemiology, Cancer Research Institute, Queen's University, Kingston, Ontario, Canada

${ }^{4}$ Institute of Applied Health Research, University of Birmingham, Birmingham, UK

${ }^{5}$ NHMRC Clinical Trials Centre, University of Sydney, Camperdown, New South Wales, Australia

Acknowledgements The authors gratefully acknowledge the support of the librarians, Rebecca Goldsworthy and Jeremy Cullis (Faculty Liaison Librarians, Sydney Medical School, University of Sydney), and Shawn Hendrikx (Clinical Outreach Librarian, Queen's University) in developing the search strategy.

Contributors RM-B, MB, MC, MRS and MTK were involved in study concept. $\mathrm{RM}-\mathrm{B}, \mathrm{MB}, \mathrm{MC}$ and MTK were involved in study design. RM-B, MJP, MB, MC and MTK were involved in data acquisition and analysis. RM-B was involved in manuscript preparation. RM-B, MB, MC and MTK were involved in manuscript editing. RM-B, MJP, MB, MC, MRS and MTK were involved in manuscript review.

Funding RM-B is supported by Sydney Catalyst, courtesy of the Cancer Institute New South Wales. MTK is supported by the Australian Government through Cancer Australia.

Competing interests None declared.

Provenance and peer review Not commissioned; externally peer reviewed.

Data sharing statement The authors have published all relevant data collected as part of this study; however, readers are invited to contact the corresponding author if further information is desired.

Open Access This is an Open Access article distributed in accordance with the Creative Commons Attribution Non Commercial (CC BY-NC 4.0) license, which permits others to distribute, remix, adapt, build upon this work noncommercially, and license their derivative works on different terms, provided the original work is properly cited and the use is non-commercial. See: http:// creativecommons.org/licenses/by-nc/4.0/

\section{REFERENCES}

1. Cherny NI, Sullivan R, Dafni U, et al. A standardised, generic, validated approach to stratify the magnitude of clinical benefit that 
can be anticipated from anti-cancer therapies: the European Society for Medical Oncology Magnitude of Clinical Benefit Scale (ESMO-MCBS). Ann Oncol 2015;26:1547-73.

2. Food and Drug Administration. Guidance for Industry: Patient-Reported Outcome Measures: Use in Medical Product Development to Support Labeling Claims. FDA, 2009. http://www. fda.gov/downloads/Drugs/.../Guidances/UCM193282.pdf (accessed 10 Mar 2014)

3. European Medicines Agency. Oncology Working Party. Draft Reflection Paper on the use of patient reported outcome (PRO) measures in oncology studies. EMA, 2014. http://www.ema.europa. eu/docs/en_GB/document_library/Scientific_guideline/2014/06/ WC500168852.pdf (accessed 2 Sept 2014).

4. Little RJ, D'Agostino R, Cohen ML, et al. The prevention and treatment of missing data in clinical trials. $N$ Engl J Med 2012;367:1355-60.

5. Bernhard J, Cella DF, Coates AS, et al. Missing quality of life data in cancer clinical trials: serious problems and challenges. Stat Med 1998:17:517-32.

6. Staquet M, Berzon R, Osoba D, et al. Guidelines for reporting results of quality of life assessments in clinical trials. Qual Life Res 1996;5:496-502.

7. Bernhard J, Gelber RD, Hürny C. Preface. Stat Med 1998;17:511-12.

8. Bylicki O, Gan HK, Joly F, et al. Poor patient-reported outcomes reporting according to CONSORT guidelines in randomized clinical trials evaluating systemic cancer therapy. Ann Oncol 2015;26:231-7.

9. Efficace F, Fayers P, Pusic A, et al. Quality of patient-reported outcome reporting across cancer randomized controlled trials according to the CONSORT patient-reported outcome extension: a pooled analysis of 557 trials. Cancer 2015;121:3335-42.

10. Fielding S, Maclennan G, Cook JA, et al. A review of RCTs in four medical journals to assess the use of imputation to overcome missing data in quality of life outcomes. Trials 2008;9:51.

11. Friedlander M, Mercieca-Bebber RL, King MT. Patient-reported outcomes (PRO) in ovarian cancer clinical trials-lost opportunities and lessons learned. Ann Oncol 2016;27(Suppl 1):i66-71.

12. Fairclough DL, Peterson HF, Cella D, et al. Comparison of several model-based methods for analysing incomplete quality of life data in cancer clinical trials. Stat Med 1998;17:781-96.

13. Fairclough DL, Peterson HF, Chang V. Why are missing quality of life data a problem in clinical trials of cancer therapy? Stat Med 1998:17:667-77.

14. Bell ML, Fiero M, Horton NJ, et al. Handling missing data in RCTs; a review of the top medical journals. BMC Med Res Methodol 2014:14:118.

15. Rubin DB. Inference and missing data. Biometrika 1976;63:581-92.

16. Tabachnick B, Fidell L. Using multivariate statistics. Needham Heights, MA: Allyn \& Bacon, 2012.

17. Bell ML, Fairclough DL. Practical and statistical issues in missing data for longitudinal patient-reported outcomes. Stat Methods Med Res 2014;23:440-59.

18. Curran D, Bacchi M, Schmitz SFH, et al. Identifying the types of missingness in quality of life data from clinical trials. Stat Med 1998; 17:739-56.

19. Dong $\mathrm{Y}$, Peng CY. Principled missing data methods for researchers. Springerplus 2013;2:222.

20. Curran D, Molenberghs G, Fayers PM, et al. Incomplete quality of life data in randomized trials: missing forms. Stat Med 1998;17:697-709.

21. Fielding S, Fayers PM, Ramsay CR. Investigating the missing data mechanism in quality of life outcomes: a comparison of approaches. Health Qual Life Outcomes 2009;7:57.

22. Moher D, Liberati $A$, Tetzlaff $\mathrm{J}$, et al. Preferred reporting items for systematic reviews and meta-analyses: The PRISMA statement. PLoS Med 2009;6:e1000097.

23. Barnett-Page E, Thomas J. Methods for the synthesis of qualitative research: a critical review. BMC Med Res Methodol 2009;9:59.

24. Gale NK, Heath G, Cameron E, et al. Using the framework method for the analysis of qualitative data in multi-disciplinary health research. BMC Med Res Methodol 2013;13:117.

25. Land SR, Ritter MW, Costantino JP, et al. Compliance with patient-reported outcomes in multicenter clinical trials: methodologic and practical approaches. J Clin Oncol 2007;25:5113-20.

26. Cella DF, Lloyd SR. Data collection strategies for patient-reported information. Qual Manag Health Care 1994;2:28-35.

27. Fallowfield LJ, Harper P. Health-related quality of life in patients undergoing drug therapy for advanced non-small-cell lung cancer. Lung Cancer 2005;48:365-77.
28. Little RJ, Cohen ML, Dickersin K, et al. The design and conduct of clinical trials to limit missing data. Stat Med 2012;31: 3433-43.

29. Walker M, Brown J, Brown K, et al. Practical problems with the collection and interpretation of serial quality of life assessments in patients with malignant glioma. J Neurooncol 2003;63:179-86.

30. Taphoorn MJ, Sizoo EM, Bottomley A. Review on quality of life issues in patients with primary brain tumors. Oncologist 2010;15:618-26.

31. Aaronson NK. Quality of life research in cancer clinical trials: a need for common rules and language. Oncology (Williston Park, NY) 1990;4:59-66.

32. Young T, de Haes D, Curran D, et al. Guidelines for assessing Quality of Life in EORTC clinical trials. Brussels: EORTC QOL Group, 2002.

33. Fallowfield L. Compliance issues in quality of life assessment: experiences of two Cancer Research Campaign sponsored groups. Stat Med 1998;17:541-6.

34. Larkin ME, Lorenzi GM, Bayless M, et al. Evolution of the study coordinator role: the 28-year experience in Diabetes Control and Complications Trial/Epidemiology of Diabetes Interventions and Complications (DCCT/EDIC). Clin Trials 2012;9:418-25.

35. Bernhard J, Gusset H, Hürny C. Practical issues in quality of life assessment in multicentre trials conducted by the Swiss Group for Clinical Cancer Research. Stat Med 1998;17:633-9.

36. Ganz PA, Day R, Costantino J. Compliance with quality of life data collection in the National Surgical Adjuvant Breast and Bowel Project (NSABP) Breast Cancer Prevention Trial. Stat Med 1998;17:613-22.

37. Wisniewski SR, Leon AC, Otto MW, et al. Prevention of missing data in clinical research studies. Biol Psychiatry 2006;59:997-1000.

38. Bernhard J, Peterson HF, Coates AS, et al. Quality of life assessment in International Breast Cancer Study Group (IBCSG) trials: practical issues and factors associated with missing data. Stat Med 1998:17:587-601

39. Hahn EA, Webster KA, Cella D, et al. Missing data in quality of life research in Eastern Cooperative Oncology Group (ECOG) clinical trials: problems and solutions. Stat Med 1998;17:547-59.

40. Cella DF. Methods and problems in measuring quality of life. Support Care Cancer 1995;3:11-22.

41. Wilcox S, Shumaker SA, Bowen DJ, et al. Promoting adherence and retention to clinical trials in special populations: a women's health initiative workshop. Control Clin Trials 2001;22:279-89.

42. Young T, Maher J. Collecting quality of life data in EORTC clinical trials-what happens in practice? Psychooncology 1999;8:260-3

43. Osoba D, Dancey J, Zee B, et al. Health-related quality-of-life studies of the National Cancer Institute of Canada Clinical Trials Group. J Natl Cancer Inst.1996; Monographs 2: 107-111.

44. Hellard ME, Sinclair MI, Forbes AB, et al. Methods used to maintain a high level of participant involvement in a clinical trial. $J$ Epidemiol Community Health 2001:55:348-51.

45. Revicki D, Fairclough D. Preventing missing data. In: Fayers P, Hays $\mathrm{R}$, eds. Assessing quality of life in clinical trials: analysis and interpretation. 2nd edn. Oxford University Press, 2005:209-222.

46. Scott RB, Farmer E, Smiton A, et al. Methodology of neuropsychological research in multicentre randomized clinical trials: a model derived from the International Subarachnoid Aneurysm Trial. Clin Trials 2004;1:31-9.

47. Hayden KA, Moinpour CM, Metch B, et al. Pitfalls in quality-of-life assessment: lessons from a Southwest Oncology Group breast cancer clinical trial. Oncol Nurs Forum 1993;20:1415-19.

48. Rouette J, Blazeby J, King M, et al. Integrating health-related quality of life findings from randomized clinical trials into practice: an international study of oncologists' perspectives. Qual Life Res 2015;24:1317-25

49. Calvert M, Blazeby J, Altman DG, et al. Reporting of patient-reported outcomes in randomized trials: the CONSORT PRO extension. JAMA 2013;309:814-22.

50. Brundage M, Bass B, Davidson J, et al. Patterns of reporting health-related quality of life outcomes in randomized clinical trials: implications for clinicians and quality of life researchers. Qual Life Res 2011;20:653-64.

51. Mercieca-Bebber RL, Perreca A, King M, et al. Patient-reported outcomes in head and neck and thyroid cancer randomised controlled trials: a systematic review of completeness of reporting and impact on interpretation. Eur J Cancer 2016;56:144-61.

52. Schandelmaier S, Conen K, von Elm E, et al. Planning and reporting of quality-of-life outcomes in cancer trials. Ann Oncol 2015;26:1966-73

53. Glasziou P, Altman DG, Bossuyt $P$, et al. Reducing waste from incomplete or unusable reports of biomedical research. Lancet 2014;383:267-76. 
54. Palmer M, Mercieca-Bebber R, King M, et al. A framework for classifying root causes of missing data for patient reported outcomes in prospective studies. Qual Life Res 2015;24:a2016.

55. Juni $\mathrm{P}$, Holenstein F, Sterne J, et al. Direction and impact of language bias in meta-analyses of controlled trials: empirical study. Int J Epidemiol 2002;31:115-23.

56. Moher D, Pham B, Klassen TP, et al. What contributions do languages other than English make on the results of meta-analyses? J Clin Epidemiol 2000;53:964-72.

57. Fairclough D. Design and analysis of quality of life studies in clinical trials. New York: Chapman \& Hall, 2010.

58. King MT. A point of minimal important difference (MID): a critique of terminology and methods. Expert Rev Pharmacoecon Outcomes Res 2011;11:171-84.

59. Wyrwich KW, Nienaber NA, Tierney WM, et al. Linking clinical relevance and statistical significance in evaluating intra-individual changes in health-related quality of life. Med Care 1999;37:469-78.

60. Calvert M, Kyte D, Duffy H, et al. Patient reported outcome (PRO) assessment in clinical trials: a systematic review of guidance for trial protocol writers. PLOS ONE 2014;9:e110216.

61. Kyte D, Duffy H, Fletcher B, et al. Systematic evaluation of the patient reported outcome (PRO) content of clinical trial protocols. PLOS ONE 2014;9:e110229.

62. Brundage M, Blazeby J, Revicki D, et al. Patient-reported outcomes in randomized clinical trials: development of ISOQOL reporting standards. Qual Life Res 2013;22:1161-75.
63. Calvert M, Kyte D, von Hildebrand M, et al. Putting patients at the heart of health-care research. Lancet 2015;385: 1073-4.

64. Tang ST, McCorkle R. Use of family proxies in quality of life research for cancer patients at the end of life: a literature review. Cancer Invest 2002;20:1086-104.

65. Gheorghe A, Roberts T, Hemming K, et al. Evaluating the generalisability of trial results: introducing a centre- and trial-level generalisability index. Pharmacoeconomics 2015;33:1195-214.

66. Rutherford C, Costa D, Mercieca-Bebber R, et al. Mode of administration does not cause bias in patient-reported outcome results: a meta-analysis. Qual Life Res 2015;3:3.

67. Cantrell MA, Lupinacci P. Methodological issues in online data collection. J Adv Nurs 2007;60:544-9.

68. Edwards $\mathrm{P}$, Roberts I, Clarke M, et al. Methods to increase response rates to postal questionnaires. Cochrane Database Syst Rev 2007; (2):MR000008

69. Osoba D, Bezjak A, Brundage M, et al. Evaluating health-related quality of life in cancer clinical trials: the National Cancer Institute of Canada Clinical Trials Group experience. Value Health 2007;10 (Suppl 2):S138-45.

70. Osoba D, Bezjak A, Brundage M, et al. Analysis and interpretation of health-related quality-of-life data from clinical trials: basic approach of the National Cancer Institute of Canada Clinical Trials Group. Eur J Cancer 2005;41:280-7. 